\title{
Hierarchical controls selection based on PV penetrations for voltage rise mitigation in a LV distribution network
}

\author{
F. H. M. Rafi ${ }^{*}$ Student Member, IEEE, M. J. Hossain, Senior Member, IEEE and J. Lu, Senior \\ Member, IEEE \\ Queensland Micro and Nano Technology Center, School of Engineering, Griffith University, Gold coast, 4215, Australia \\ *Fida.rafi@griffithuni.edu.au, j.hossain@griffith.edu.au, j.lu@griffith.edu.au
}

\begin{abstract}
In recent years, the penetration level of distributed energy resources (DER) in the low voltage (LV) networks are increasing rapidly which has resulted in causing the voltage rise problem, even at the far end customer point in distribution networks (DNs). This paper presents a coordinated hierarchical controls selection method for mitigating the overvoltage problem using available resources in DNs, for example, static synchronous compensators (STATCOM) and battery energy storage (BES) systems. The proposed method recommends the installation of new control devices, such as photovoltaic (PV) smart voltage source inverter (VSI) with reactive power compensation capability, residential BES installations, and power sharing among neighboring distributed generator (DG) units depending on PV penetration levels at the LV network. The requirements of the proposed installation of the compensation devices are based on three criteria: (i) higher PV penetration scenarios; (ii) satisfying relevant standards; and (iii) economic perspectives. The interactions among standard VSI (operated at unity power factor (pf)) and smart VSI (variable pf) are also considered in the proposed method to mitigate the voltage rise problems. The results show that only after exceeding certain PV penetrations, the LV network requires a coordinated operation from STATCOM/BES and advanced compensation devices to sustain terminal voltages within permissible $( \pm 6 \%)$ limits. The proposed method is verified with extensive case studies utilizing real PV irradiance and customer loads data with nonlinear dynamic DER models connected with an urban LV network in the PSCAD/ EMTDC software environment.

Index Terms-- High PV penetration, STATCOM/BES, smart PV-VSI, residential BES, voltage rise, LV network.
\end{abstract}

\section{INTRODUCTION}

$\mathrm{T}$ The proliferation of distributed energy resources (DER) integration in the traditional distribution networks is conspicuous, especially in the LV networks. Among different types of DER units, rooftop PV systems are the most popular and widely implemented, due to special government incentives in many countries, as well as the ease of installation in both small and large scales. Increasing PV penetrations in the LV network is changing the DN from passive to active, i.e. power flow is not only unidirectional from generators to loads it is now bidirectional, which causes dramatic effects, such as voltage rise and poor power quality [1].

For mitigating voltage related problems, different compensation devices, such as capacitor banks, flexible ac transmission system (FACTS) devices, on/off load tap changing transformers (OLT), and automatic voltage compensator (AVC), have already been applied for stability restoration on the HV and MV networks [2]. Within the last decade, the total PV installations, worldwide, increased to approximately $135 \mathrm{GW}$, with Australia ranking in the top $9^{\text {th }}$ position, with more than 3GW PV installations. Rooftop PV units in the LV networks contribute 43\% to the total installations; Queensland's installations alone covers one third of the total PV capacity [3]. Energex, the local distribution network operator (DNO) in Queensland, supports approximately 570 MW PV installations in their DNs [4] [5]. Despite the increasing PV installation numbers, local DNOs do not allow voltage regulation at the customer's end in most Australian LV networks. With the stringent PV connecting standards, voltage compensation devices are becoming more popular in the LV networks. The high PV installed countries, such as Germany and Italy, have already started the application of local voltage support at PV installations, as local regulations provide better network stability than traditional centralized solutions [6-8]. One highly installed local dynamic compensation device in the LV network is the distribution STATCOM (D-STATCOM), especially in places where a smart VSI operation is not permitted. The combined operation of BES with STATCOM can provide an additional degree of freedom for the independent control of active and reactive powers, which has resulted in more demand for centralized BES installations in the LV networks [9].

During peak PV generation periods, the total PV power, after load compensation, is directly fed back to the distribution grid. After reaching a certain PV penetration level, namely, when it exceeds the maximum limit of existing DNs, the reverse flow of power causes voltage violations at the point of common coupling (PCC), i.e. exceeding $+6 \%$, resulting in the unwanted tripping of PV units. Generally, absorbing certain levels of reactive power, i.e. lagging power factor (pf) operation, from the highly PV penetrated networks can prevent the unnecessary tripping [10] [11]. Compensation controls are commonly applied using DSTATCOM, mechanically switched capacitor banks, and OLTs in the LV networks. As a traditional LV distribution network 
exhibits low $\mathrm{X} / \mathrm{R}$ ratio (less than 1 ), i.e. resistive type nature, in some cases, voltage regulation utilizing active power regulations such as BES charging, proves more effective than reactive power compensations [12], [13].

The BES has been commonly used as backup support and additional operations, such as, frequency control, flicker mitigation, phase balancing, transmission line loss reduction, and grid capacity improvement to relieve additional pressure from passive grid networks [14]. Authors in [15] propose power sharing controls among residential BES during peak PV generation periods for voltage regulation purposes. However, with the current price of BES installations, the required regulation operation will incur additional cost to the customers. Similarly, emerging plug in hybrid vehicle (PHEV) is utilized for peak PV charging operation to reduce the electricity bills and voltage regulation in [16]; however, this requires stringent charging scheduling to obtain effective results. Operating the DG units at lower maximum power point (MPP) than the rated one (active power curtailment) has been proposed for renewable energy units in [17] [18]. The power curtailment method contradicts the maximum resource utilization concept, and results are only presented for the rather smaller feeder connections. With the aim of reactive power loss reduction, due to DG penetrations, authors in [19] propose a coordinated reactive power management method designing load flow models; however, applicability in the LV network is not presented. Alternatively, regulating specific loads, such as thermal storage heaters and hot water storage system, is an effective way of reducing voltage rise during peak DG generations [20] [21]. Nevertheless, this requires higher installation costs and exhibits slower voltage restoration. Utilizing fast artificial dynamic systems with the sensitivity theory, authors in [22] propose a centralized real time control of reactive power from PV inverters for voltage regulation, but this is only applied to the MV distribution networks.

Due to the active nature and highly resistive line characteristics of the DN, centralized controls have less impact on the far end users experiencing voltage rise problems. Therefore, decentralized controls are becoming imperative and much significant research has been undertaken utilizing reactive power support from modified PV-VSI in literatures [23]-[26]. Authors in [27] compared the centralized and distributed controls based on optimal power flow (OPF) methods, while the benefits of decentralized controls with minimum communication requirements have been exploited by the authors in [28]. Utilizing demand shifting operations to achieve higher renewable energy penetration at the European LV networks, authors in [29] applied the Monte Carlo sensitivity analysis to consider the flexible demand topology for end customers. However, the impact of compensation devices, as well as future PV penetration cases, has not been considered. Decentralized active power curtailment and local reactive power supports with minimum communication were proposed by the authors in [30]. Despite with the improved voltage profile, the curtailed power will still cause waste of energy, and challenges about how the power sharing will be utilized with the unity pf VSI are not mentioned in this paper [30]. Considering the Australian LV networks, authors in [31] and [32] propose local reactive power and residential BES control operations for voltage regulation. However, as the grid connection standard is still stringent about local reactive power support, determining at what condition local controls will be imperative rather than optional has not been addressed properly. Also, needing consideration is that the traditional DNs are capable of sustaining certain amounts of PV penetration without any voltage constraints issues; therefore, the advanced compensation devices are not necessarily required for voltage mitigation unless it exceeds certain PV penetration levels.

Contribution: This paper proposes a hierarchical controls selection method for voltage rise mitigation based on PV penetration levels in the LV network, both for summer and winter seasons. The main objective is to accommodate increasing PV penetrations without any voltage constraint issues. Unlike [27] and [31], the DN is considered as the primary voltage regulator, and upon failure of DN regulation, a decentralized dynamic voltage regulation device, STATCOM/BES, is considered. Finally, the emerging local regulation solutions, such as smart PV-VSI with fixed reactive power capability [33], residential BES installation and power sharing among neighbor DG units, are considered. The control selection is dominated by factors such as the cost effectiveness of the present situation, connecting standards, and device availability. Local supports from customers' installations are considered only after the failure of centralized regulation operations. The application of the proposed algorithm is analyzed in the complex mesh/loop LV network using real field test data. The combined operation of unity pf and smart VSI is also considered for the regulation purpose. Unlike [15], the requirement of residential BES installation is considered only for specific customers in critically voltage sensitive areas. Therefore, the customers do not necessarily need to install the BES as a pre-requirement of PV interconnection to the already PV saturated local grids. Power sharing among neighbor DG units is considered as the last regulation solution and proves to be an effective one, even with the highest PV penetration level. The proposed power sharing method in this paper requires minimum communication between the centralized STATCOM/BES and distributed PV units only when other compensation solutions fail to regulate the voltage rise. The communication can be performed using simple distress signaling via power link communication [30], [34]. With the close proximity among urban area customers, four quadrant smart meters can also be utilized for the communication purpose via RS485 [33]. Instead of utilizing constant current/voltage sources or optimized DER models, the proposed method is implemented with dynamic DER units to verify its efficacy in real life scenarios.

Synopsis: The rest of the paper is organized as follows; in Section II, the modelling of dynamic components is presented. The proposed control methodology is discussed in section III and, results from different case studies are presented in Section IV. In section V, a cost comparison with existing solutions is presented, and the paper is concluded stating future works in Section VI. 


\section{DERS DYNAMIC MODELLING}

The detailed model of the significant devices under consideration, for example, PV units, VSI, STATCOM, BES and the LV network, are described below.

\section{A. PV units:}

Real life PV systems exhibit nonlinear characteristics due to variations in sun irradiance, temperature, and cloud passing. To capture the nonlinear characteristics and provide approximate real life performance, the dynamic PV modules are developed using several series and parallel connected arrays and the irradiance data is utilized from actual PV installations at Griffith University. The PV system consists of two sections: i) PV modules with dc-dc converter; and ii) interlinking power electronics interface voltage source converters (VSC) between the dc and ac side. The maximum power point tracking (MPPT) operation is commonly integrated with the dc-dc boost converter. In this paper, a single stage PV system is considered which requires higher dc bus voltage for independent active and reactive power controls [24] [35]. The single stage control reduces energy losses associated with multistage energy conversion and also provides faster dynamic control responses (due to time delay reductions from the dc-dc conversion stage). The detailed connection diagram of the PV and residential BES units with the interlinking VSI, LCL filter, residential loads, and the grid interconnection is shown in Fig. 1.

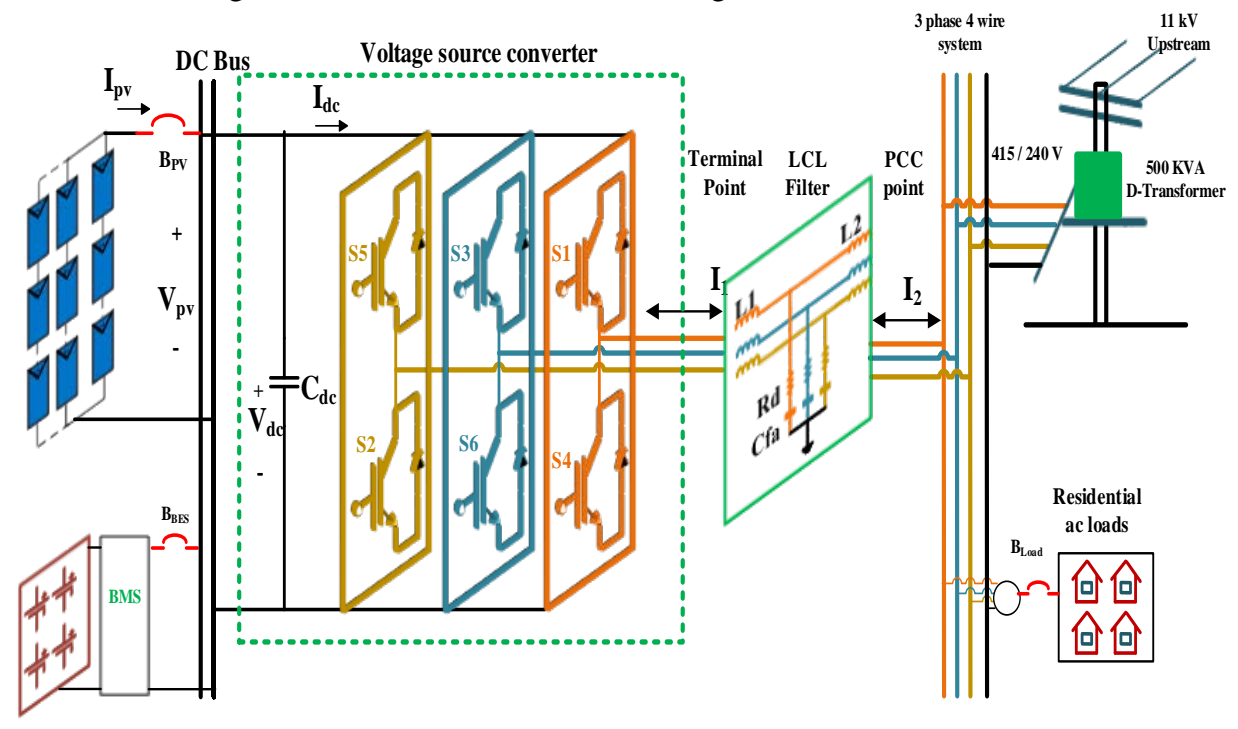

Fig. 1. Single PV unit and BES detailed connection diagram.

The PV power generation and corresponding single stage VSI switching dynamics equations with LCL filter can be found in the literature [24], [36]. The instantaneous active and reactive power from the PV VSI after the dq0 transformation can be written as;

$$
\begin{aligned}
\mathrm{P}_{\mathrm{pcc}} & =\frac{3}{2}\left(\mathrm{E}_{\mathrm{dpcc}} \mathrm{I}_{\mathrm{dpcc}}+\mathrm{E}_{\mathrm{qpcc}} \mathrm{I}_{\mathrm{qpcc}}\right) \\
\mathrm{Q}_{\mathrm{pcc}} & =\frac{3}{2}\left(\mathrm{E}_{\mathrm{qpcc}} \mathrm{I}_{\mathrm{dpcc}}-\mathrm{E}_{\mathrm{dpcc}} \mathrm{I}_{\mathrm{qpcc}}\right)
\end{aligned}
$$

The synchronous reference frame transformation $(a b c-d q 0)$ with the phase locked loop (PLL) results in the point of common coupling (PCC) voltage q component to follow zero, i.e. $\mathrm{E}_{\mathrm{qpcc}}=0$, and equations (1) and (2) can be written as;

$$
\mathrm{P}_{\mathrm{pcc}}=\frac{3}{2} \mathrm{E}_{\mathrm{dpcc}} \mathrm{I}_{\mathrm{dpcc}} \& \mathrm{Q}_{\mathrm{pcc}}=-\frac{3}{2} \mathrm{E}_{\mathrm{dpcc}} \mathrm{I}_{\mathrm{qpcc}}
$$

where, $\mathrm{E}_{\mathrm{d}}, \mathrm{E}_{\mathrm{q}}, \mathrm{I}_{\mathrm{d}}$, and $\mathrm{I}_{\mathrm{q}}$ are the PCC voltage and current components after $a b c$ - $d q$ transformation.

\section{B. STATCOM and smart VSI:}

The STATCOM is a shunt connected VSC which is mainly used for dynamic voltage restoration, flicker mitigation and utility pf correction by controlling the angle between the converter and the grid voltages. Depending on the system requirement, it can inject reactive power, i.e. inject capacitive current, or it can absorb reactive power, i.e. absorb inductive current to/from the connected system. One of the main reasons for the wide application of STATCOM in a dynamic analysis is its characteristics of having control over its rated current, despite the reduction in the connection point voltage [37]. The basic dynamic model of PV VSI and STATCOM VSC is similar in construction, the first focuses mainly on active current control, while the second focuses mainly on reactive current control. The VSCs in both devices are capable of controlling the injected voltage magnitude and phase angle. The dc capacitor with the VSC is used to get constant dc voltage for the VSC switching mechanism.

A similar control concept can be applied for the PV smart VSI with reactive compensation capability. As the total capacity of the VSI is designed to handle maximum a PV output during peak PV periods, except during mid-day, the PV VSI cannot use its 
full capacity. For example, for a standard testing condition (STC), a 5 kVA PV unit can supply around 4.3-4.5 kW after compensating for line and switching losses. If the sun radiation becomes less than the STC, the VSC will only supply the reduced active power and will have some unused capacity available during the day and almost full capacity during the night time which can easily be calculated using $Q_{V S C}=\sqrt{S_{V S C}^{2}-P_{V S C}^{2}}$, where, $\mathrm{S}_{\mathrm{vsc}}, \mathrm{P}_{\mathrm{vsc}}$ and $\mathrm{Q}_{\mathrm{vsc}}$ are the apparent, instantaneous active, and reactive powers. For unity pf VSI, the $\mathrm{Q}_{\mathrm{Vsc}}$, and for STATCOM, the $\mathrm{P}_{\mathrm{VSC}}$ is generally set to zero. Therefore, unity pf VSI cannot utilize the unused capacity from PV installations. For smart PV-VSI, the Qvsc is set to the fixed pf 0.95 lagging control following the Australian connecting standards. Moreover, the unused Qvsc is utilized for power sharing among neighbor DG units upon requirement. From equation (3), it can be seen that, the active and reactive power of the VSC can independently be controlled by controlling the $\mathrm{I}_{\mathrm{dpcc}}$ and $\mathrm{I}_{\mathrm{qpcc}}$ current references. The current references can be determined as [37];

$$
\mathrm{I}_{\mathrm{dref}}=\frac{2}{3} \frac{\mathrm{Ppcc}_{\mathrm{pcc}}}{\mathrm{E}_{\mathrm{dpcc}}} ; \mathrm{I}_{\mathrm{qref}}=-\frac{2}{3} \frac{\mathrm{Qpcc}_{\mathrm{pcc}}}{\mathrm{E}_{\mathrm{dpcc}}} \text { and } \quad \mathrm{E}_{\mathrm{dpcc}}=-\frac{2}{3} \frac{\mathrm{Qpcc}_{\mathrm{pcc}}}{\mathrm{I}_{\mathrm{qref}}}
$$

The $Q_{p c c-r e f}$ can be calculated via external control loops like PCC voltage regulation, pf correction, VAR compensation, etc. In this paper, the PCC voltage rise regulation is mainly focused on the both STATCOM and smart VSI operations. The PCC voltage can be regulated controlling the $E_{\mathrm{d}-\mathrm{pcc}}$ voltage component, as seen from equation (4). For STATCOM and smart VSI, two external control loops, one for dc voltage and one for the PCC rms voltage regulation has been designed. Both leading and lagging p.f control operations are considered for the STATCOM, whereas only lagging pf operation is considered for PV smart VSI. The internal decoupled current control loops utilize the references from the external loops and generate the modulating signals for the VSC switching mechanism. The traditional pulse width modulation (PWM) switching is applied for the six pulse VSCs in both the STATCOM and PV inverters (both unity and smart). The detailed control structures are shown in Fig. 2. The individual control loops and the plant transfer functions are linearized following ref. [38] and the PI gain values are initially set using the symmetrical optimum tuning method. To reduce the harmonic contents generated from the switching signals and external noises, the LCL filter is designed and implemented with all the PV and STATCOM units [39].

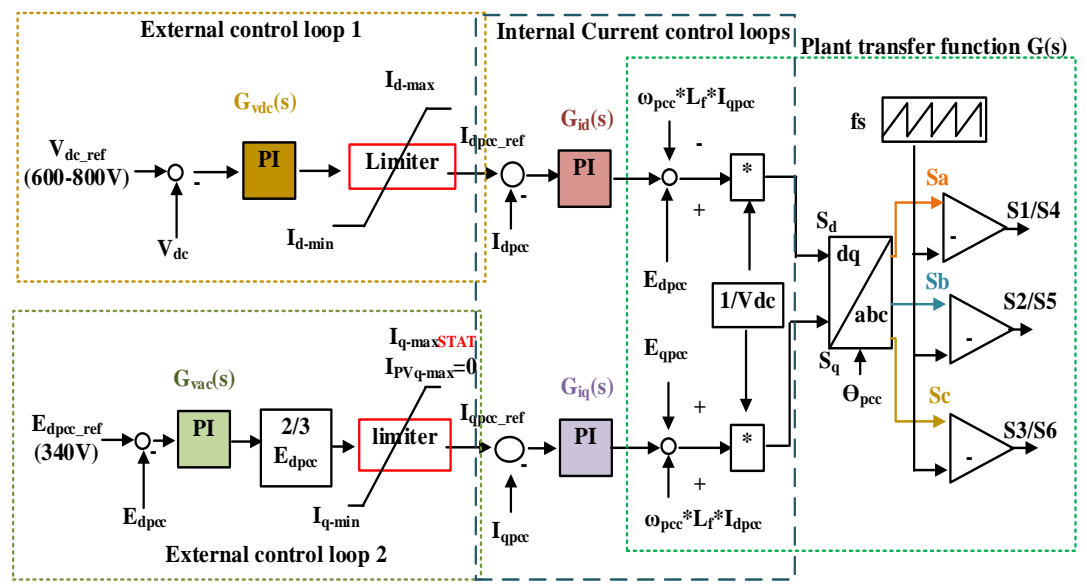

Fig. 2. Control structure of the STACOM and smart VSI.

\section{BES modelling:}

Two types of battery installations are considered in this paper: i) BES with the STATCOM, and ii) residential BES with the rooftop PV units. Both of the BES are been designed following the popular battery model from references [15] and [40]. The battery model is chosen because of its dynamic characteristics, namely, state of charge (SOC) dependent battery terminal voltage and its simplicity in battery parameters determination. The battery parameters can easily be calculated following the BES discharge curve provided by the manufacturers. A separate battery monitoring and management system (BMMS) has been designed using a bidirectional dc-dc converter, connected with the dc bus line. Instead of connecting the BES directly to the dc bus, using the BMMS system, the BES terminal voltage requires only half of the dc bus voltage.

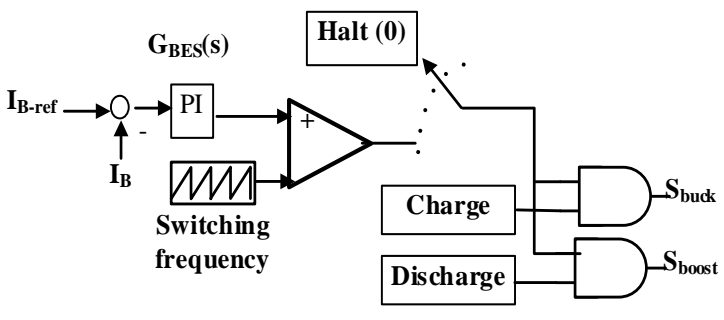

(a)

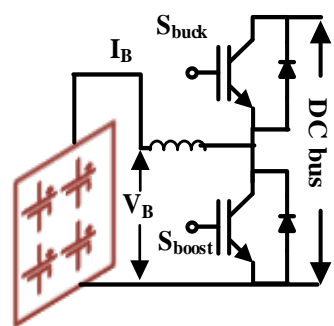

(b)

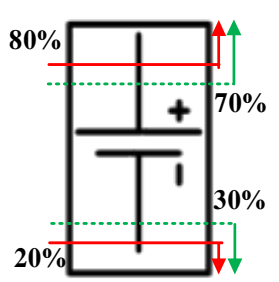

(C)

Fig. 3. (a) BMS logic diagram, (b) BES connection diagram with the dc bus, and (c) SOC limits. 
Depending on the battery size, the maximum and minimum $\mathrm{I}_{d}$ current limit is chosen for the BES charging and discharging operations in Fig. 2. The BMMS uses the switch $S_{\text {buck }}$ for the charging operations, and switch $S_{\text {boost }}$ for the discharging operation using voltage buck and boost operations. To prevent overloading in the VSC controls, the constant current charge and discharge method is utilized, and the charging/discharging command is processed monitoring the battery SOC, PV generation, load demand, and power sharing requirement, as shown in Fig. 4. However, non-uniform rate of charge and discharge can also be incorporated with the designed BMMS controls for flexible BES operations.

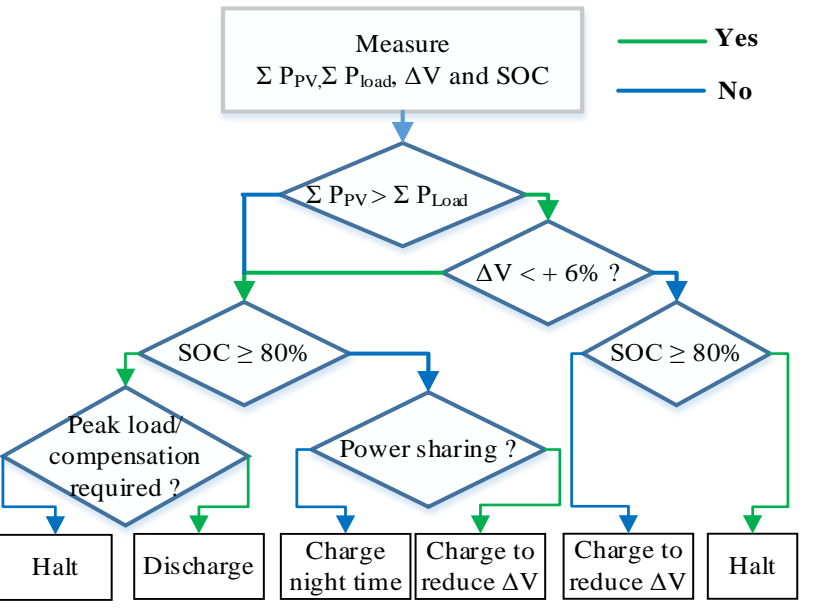

Fig. 4. BES charge/discharge flow chart.

\section{LV network design}

The LV network (11 kV/ $415 \mathrm{~V}$ ) is designed from the 33/11 kV upstream network using the distribution transformer (DT) and transmission poles data from the inner northern residential suburb of Brisbane, and provided by Energex, one of the largest DNOs in Queensland, Australia. The New market zone $11 \mathrm{kV}$ substation comprises around 2,373 customers with 8,495 kVA installed loads. The feeder minimum load is around $70 \mathrm{~A}$ and, at mid-day, is around 100A. Maximum summer and winter load currents are 150A and 250A, correspondingly. Individual customer loading has been considered as a maximum $2 \mathrm{kVA}$ and a minimum $0.55 \mathrm{kVA}$ with a power factor of 0.95 lagging. The base loading of the network is around $230 \mathrm{~kW}$ and $60 \mathrm{kVAR}$. The LV network consists mainly of three phase four wire overhead distribution lines, which is supplied from one $750 \mathrm{kVA}$ DT to 150 customers. One year loading data for the individual customers is fed to the designed power system computer aided design (PSCAD) network by calculating the resistive (R) and inductive (L) load values from active and reactive power consumptions. The LV network consists of two mesh/loop networks and the placement of the STATCOM/BES is considered following the field test data from Energex. For the PV penetration analysis, 6 farthest end points and 2 middle points have been considered in the LV network. The distance of the test points and overhead cables specifications are shown in Table 1 and 2 in Appendix.

Fig. 5. LV network, Newmarket zone, Brisbane.

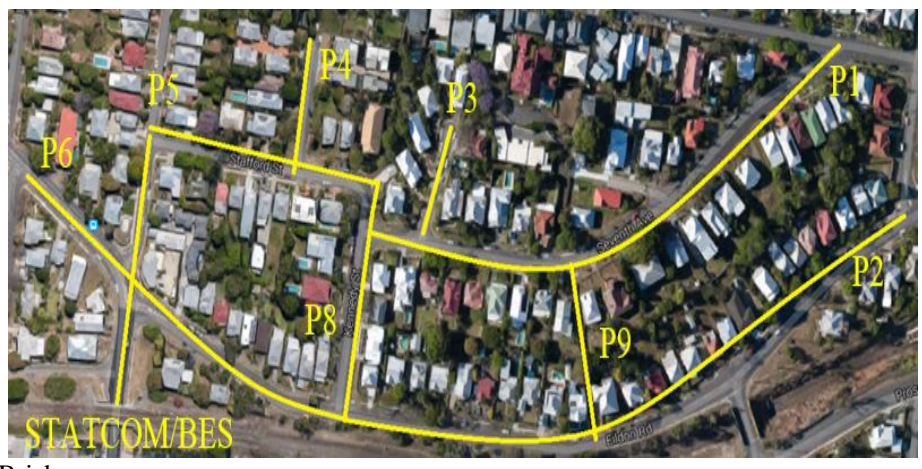

\section{VOLTAGE RISE MITIGATION METHODOLOGY}

The traditional LV networks are capable of housing certain levels of PV penetration without any major issues, even with the unity pf PV inverters. Energex, local DNO Australia, permits around 30\% PV penetration in to their LV networks [33]. With the increasing number of PV installations within Australia (recorded from 8000 to 1.4 million within last 7 years [41]), the allowable penetration level is expected to be exceeded in the very near future. The threshold point, i.e. when the additional compensation devices will become more practical to implement rather than optional, needs to be identified. This paper incorporates the gradual requirements of device installations for voltage rise mitigation. The voltage rise is considered to occur as a result of the high PV generation with a low demand case, which resembles typical residential area characteristics during the day time. Therefore, the first priority for the control selection is given to the condition of total $\mathrm{PV}$ generation $\left(\Sigma \mathrm{P}_{\mathrm{pv}}\right)$ and the total load demand ( $\Sigma \mathrm{P}_{\text {demand }}$ monitoring. The developed selection algorithm is shown in Fig. 6. 
Mode A. Normal network controls ( $\left.\Sigma P_{p v}<\Sigma P_{\text {demand }}\right)$ :

If the total PV generation $\left(\Sigma \mathrm{P}_{\mathrm{pv}}\right)$ in a particular area is less than the load demand $\left(\Sigma \mathrm{P}_{\text {demand }}\right)$, the system will continue its operation in normal control mode, such as for monitoring system faults, voltage regulation during high load demand, frequency regulation etc. The STATCOM/BES is considered to be available during normal operating mode. The power flow in the mesh/loop network exhibits more complicated control characteristics than traditional radial networks, due to the presence of multiple paths for the controlled current to flow. In complex network configurations, the STATCOM/BES helps to restore the system's normal operation more robustly than SATCOM’s operation alone.

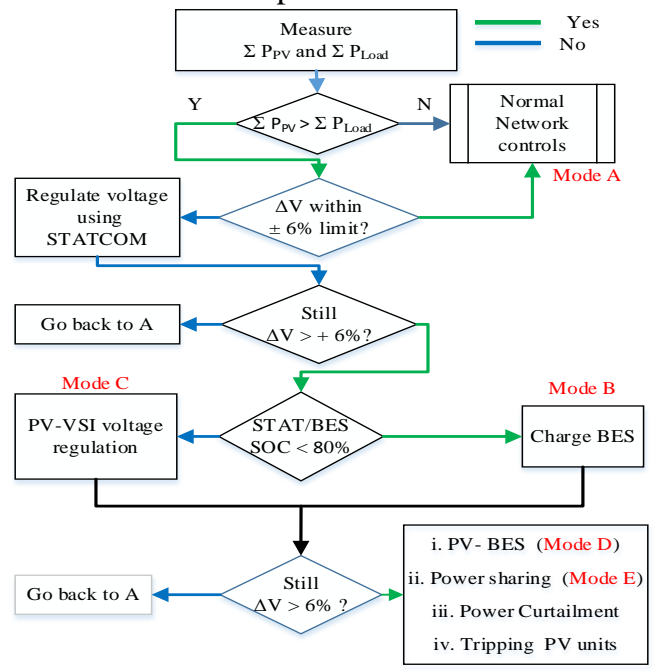

Fig. 6. Hierarchical control selection flow chart.

If the PV penetration remains less than 30\%, i.e. 5 customers each having $5 \mathrm{kVA}$ units in individual testing points, and total PV installations around $200 \mathrm{kVA}$ in the span of an approximately $2 \mathrm{~km}$ long LV network (ring); it is considered as a normal operating mode in this paper, and traditional STATCOM/BES operations along with grid supports are considered enough to stabilize the overall network, even in the case of system faults and sudden load changes.

\section{Mode B. STATCOM/BES charging control:}

If the PV penetration is higher than $30 \%, \Sigma \mathrm{P}_{\mathrm{pv}}>\Sigma \mathrm{P}_{\text {demand }}$ and PCC voltage is higher than 1.06 p.u (voltage difference $(\Delta \mathrm{V})>$ $+6 \%$ ), then initially the STATCOM will try to regulate the terminal voltage with its full capacity VAR support. In a case, if the $\Delta \mathrm{V}$ still remains higher than $+6 \%$, the control will initiate the BES charging operation, otherwise it will return to the control mode A. Generally, the BES associated with the STATCOM is considered for specific operations like DG intermittency impact reduction and oscillation smoothing. The BES charging during PV peak generation can also be considered as an effective solution for voltage regulation purposes [42]. The BES is commonly charged during late night periods, due to low tariff rates. If day time charging is required, the BES charging schedule needs to be set until the upper minimum level (SOC 70\%) during the night time, and some capacity is kept available for day time charging requirements. Deep charging operation is avoided so as to increase the BES life cycle. If the control mode B improves the voltage profile, the BES charging will be switched to the halt mode, while the STATCOM will continue to regulate the terminal voltage in the normal operating mode. Otherwise, the designed algorithm will select the control mode $\mathrm{C}$ for further compensation requirements.

If the PV penetration exceeds more than 50\%, additional supporting devices beside STATCOM/BES are required to keep the PV installed customers connected to the network without causing any major grid problems. From literatures, widely suggested additional voltage processing controls are:

i. PV smart VSI with reactive power regulation;

ii. PV peak charging from customer BES installations;

iii. Neighbour DG units’ power sharing;

iv. Active power curtailment and

v. Tripping of a particular PV section.

The last two solutions (iv and v) are avoided in this paper due to their low efficiency and less reliability operations.

Mode C. STATCOM/BES with individual PV-smart VSI:

Among the existing control options as mentioned above, the PV smart VSI with reactive power capability is one of the most researched topics; in some countries, such as Germany and Italy, this control has already been applied for local voltage regulation. Due to the additional cost of BES installation and communication link requirements for power sharing controls, the smart VSI strategy is considered as the most cost effective compared to other solutions at a PV penetration higher than 50 \% case. The theory behind the smart VSI is the principle of de-rating power controls. The de-rated controls select a new active power limit $\left(\mathrm{P}_{\text {modified }}\right)$ creating some capacity available for reactive power operation. Generally, the reactive power capability 
curve is provided by the local DNOs to restrict the over usage of smart VSI operation [30]. Very recently, in Australia, few DNOs allow smart VSI installation with fixed 0.95/0.90 pf lagging operations [33], [43]. Therefore, if the operating mode B fails to regulate the terminal voltage of a specific area, depending on the size of the PV installations, fixed 0.95/0.90 pf lagging support has been applied. In this paper, rather than following a specific capability curve, either a fixed lagging or unity pf operation is considered. The smart VSI operation can also be considered as distributed local control; therefore, minimum communication is required. The important consideration here is that, till certain PV penetrations, the unity pf VSI will be installed in to the network. And after the failure of available supporting devices, the requirement of the PV system with smart VSI installation becomes prominent. In that kind of situation, customers and DNOs can easily come to a mutual considerations for local VAR supports for mutual benefits.

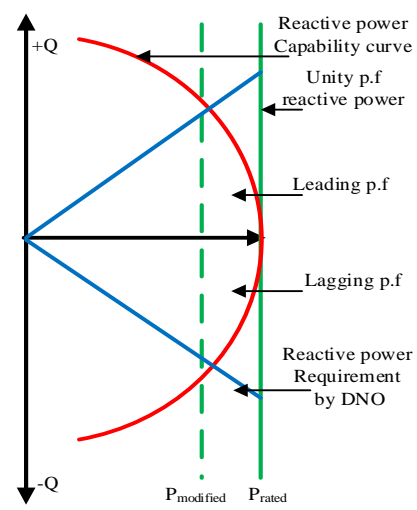

Fig. 7. De-rated PV-VSI operating curve.

If the combined operation of STATCOM/BES and the local VAR support fails to regulate voltage rise, residential BES installation is chosen as the next control to be included for voltage regulation purposes. After exceeding $65 \%$ PV penetration, which is around 100 customers with $5 \mathrm{kVA}$ units, residential BES installation with peak PV charging becomes most cost effective and an imperative control technique for voltage rise mitigation.

Mode D. STATCOM/BES, PV- smart VSI and residential BES:

The application of BES as an uninterruptible power supply (UPS), in rural areas is quite popular. In contrast, in urban areas, the installation of BES is an optional task (not imperative), resulting in less motivation towards the wide installation of BES. With reduced feed-in tariff (FIT) schemes, it can be anticipated that BES installation with the PV units will provide better economic and technical solutions by utilizing generated power for household demand reduction, rather than for feed back to the grid. If control mode D, with residential BES charging, fails to regulate the voltage within limits, the active and reactive power sharing among neighboring DG units are considered as the best possible solution to accommodate more PV installations. If the PV penetration exceeds more than 85\%, i.e. 125 customers with 5 kVA PV units, power sharing becomes the most imperative solution.

\section{Mode E. STATCOM/BES with neighbor DGs power sharing:}

Power sharing among different DG units in the microgrid, either grid connected or islanded, is one of the challenging research topics for smart microgrid area. There are many autonomous power sharing methods, such as fixed and variable droop controls, are available with minimal communication requirements, as discussed in the introduction. However, power sharing among DG units in the mesh/loop LV network is more challenging than the simpler radial distribution networks. This is due to the controlled current division characteristic in multi path networks. To make power sharing control simpler with minimum communication requirements, the control mode $\mathrm{E}$ is proposed only when all the combined operations, stated above, fail to regulate the voltage profile and power quality degrades. The oscillated output power created from poor power quality can also be improved utilizing power sharing, as shown in next section at case studies G.

The PCC terminal voltages, smart VSI reactive current limit, SOC of the residential BES, and PV generation are considered as the decision making factors related to the power sharing control selection. If all the parameters exceed their maximum allowable set limits, only then is the power sharing for specific areas experiencing voltage rise be enabled. The logical operation for that situation is shown in Fig. 8 (a). Figure 8 (b) shows the control selection method based on the PV penetration level for the designed system.

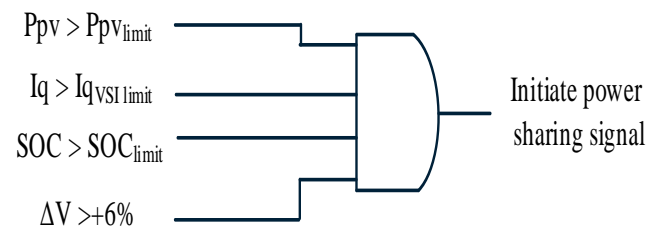

(a)

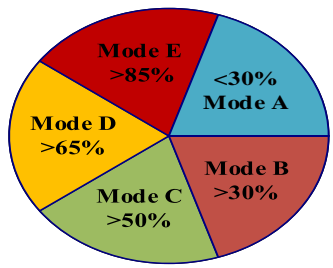

(b) 
Fig. 8. (a) Power sharing signal initiation, and (b) Operating modes selection based on PV penetration levels.

\section{RESULTS AND DISCUSSIONS}

The LV network consists of both three- and single-phase customer connections, while the distance between each customer is within 10-15 m. The X/R ratio is assumed as unity. To reduce simulation time, clustered PV installations are considered rather than individual customer PV installations. For example, single $50 \mathrm{~kW} \mathrm{PV}$ is presented for 10 customers with $5 \mathrm{kVA}$ PV installations capacity. Similarly, local reactive power support is considered utilizing the accumulated kVAR rating from 10 customers having 0.95 pf lagging characteristics. A 5 kVA PV unit with 0.95 pf lagging operation should support 2 kVAR. Therefore, a total $20 \mathrm{kVAR}$ rating is considered equivalent to 10 customers' installation at each testing points. The PV units and other inverter parameters are shown in Table 3 in Appendix.

It is estimated that, under a standard testing condition (STC), the PV module generates around $650 \mathrm{~W}$. The peak voltage and current of a single PV module are around $81 \mathrm{~V}$ and 8.125 A for 108 cells in series and 4 cells in parallel connections. The open circuit PV module voltage is around $900 \mathrm{~V}$ [44]. The BES voltage is considered around $320 \mathrm{~V}$ with a maximum charge/discharge current around $40 \mathrm{~A}$ for the $20 \mathrm{kWh}$ clustered residential units (2 kWh for each customers) and around $60 \mathrm{~A}$ for the $30 \mathrm{kWh}$ for the STATCOM unit. The STATCOM capacity is set around $30 \mathrm{kVA}$ with the maximum current limiter set at \pm 60 A. As the voltage dip scenario is not correlate with the increasing PV penetration levels; therefore, it is shown only with the STATCOM/BES operations with different faults. A 44 bus LV network diagram with the considered test points and STATCOM/BES location is shown in Fig. 9. The distances among the distribution transformer and the test points are given in Table 1 in appendix. The worst case, with a high PV generation and low load demand, is considered for summer and winter seasons for consecutive three days, from 6 am to $5 \mathrm{pm}$. The analysis results are presented in the case studies discussed below.

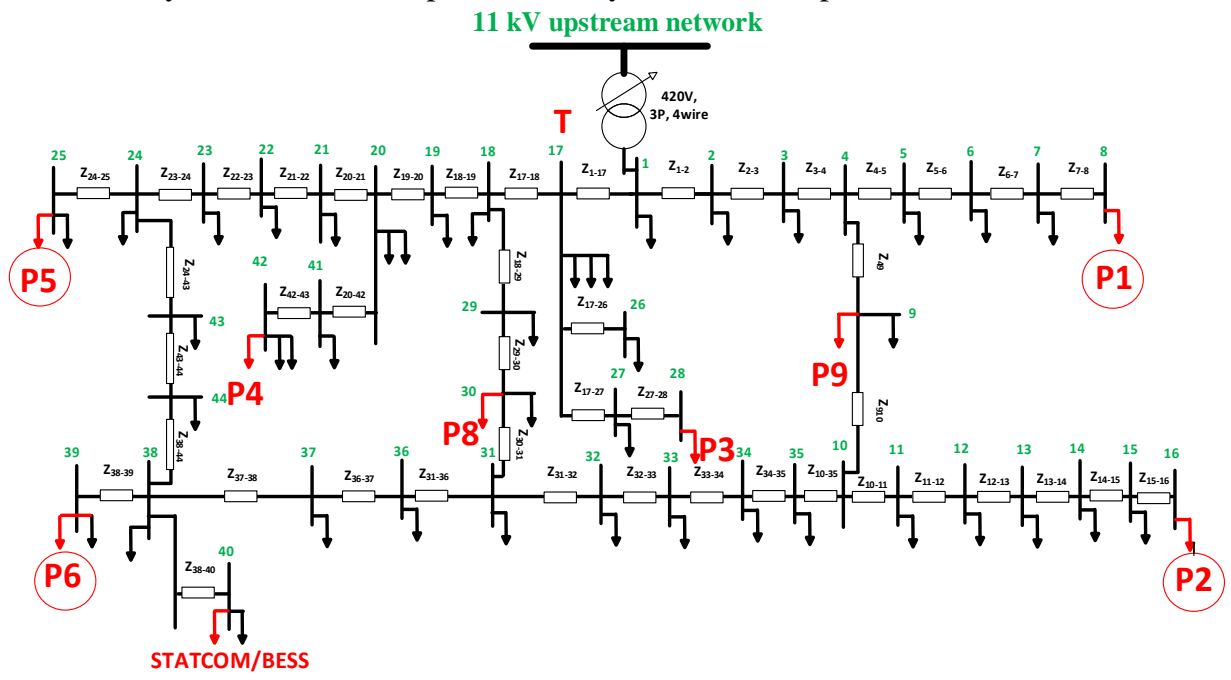

Fig. 9. 44 bus residential LV network connection diagram.

A. Residential load profiles during summer and winter:

The load requirement varies in different seasons. In addition to the normal household loads, the active power demand is higher during winter, due to the application of resistive type heaters, whereas reactive power demand is higher in summer because of running air-conditioning devices. Similarly, the power generation from rooftop PV units is higher during summer than during winter, due to weather characteristics. Typical residential load profiles with a $10 \mathrm{kVA}$ PV unit during summer and winter, are presented in Figs. 10 (a-c).

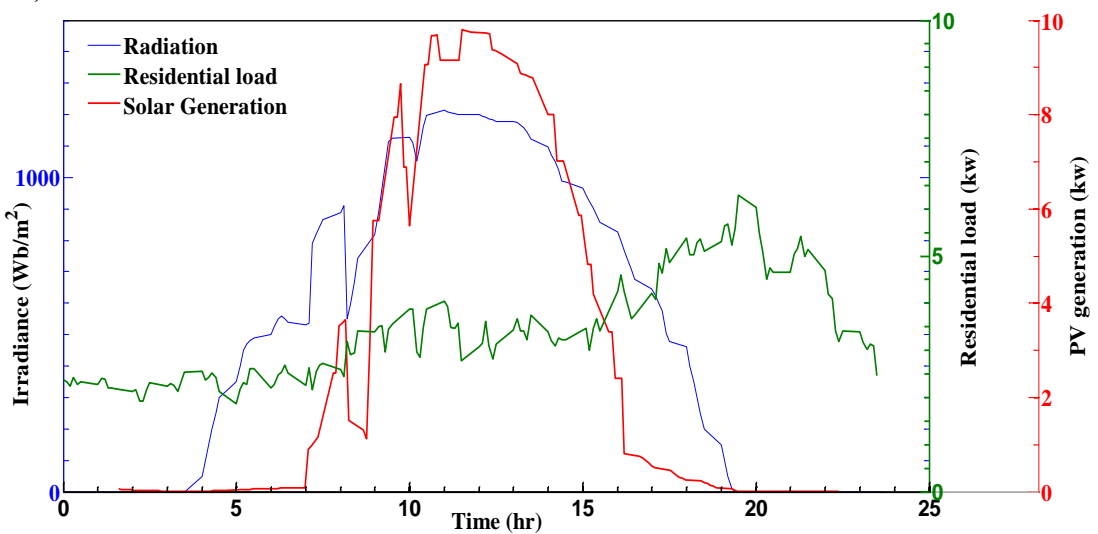

(a) 


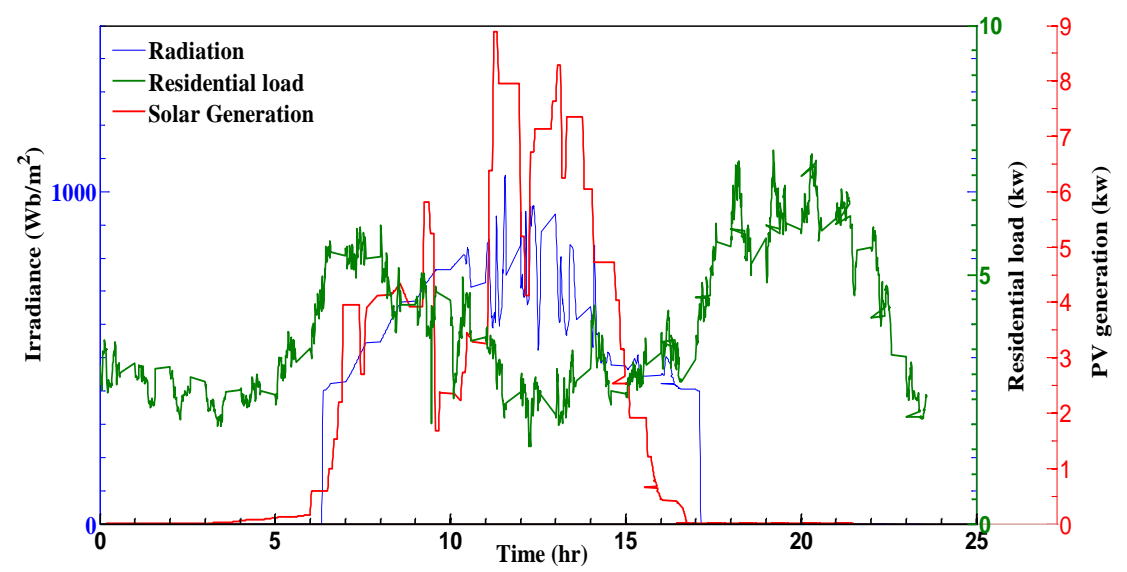

(b)

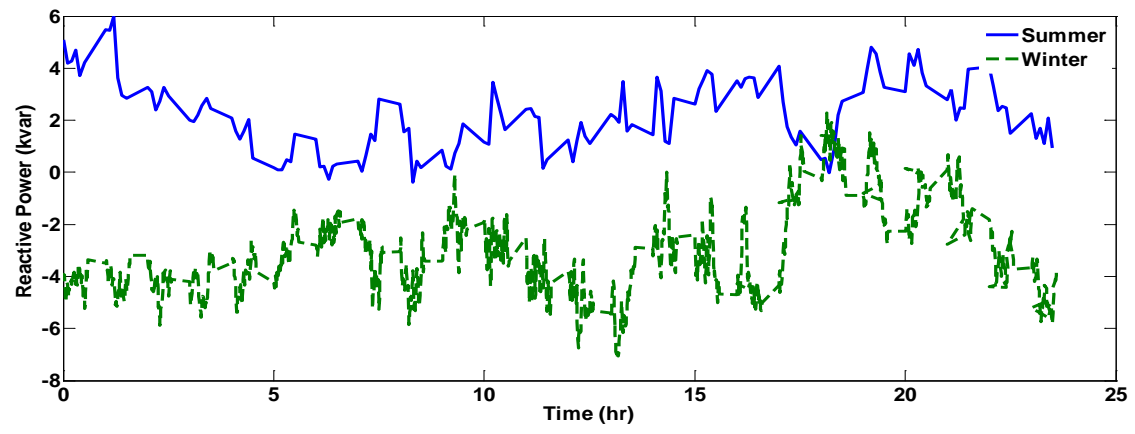

(c)

Fig. 10. Residential PV generation and load demand profile during (a) summer, (b) winter, and (c) reactive power profiles.

\section{B. Initial test analysis at STC:}

For the LV system, the initial analysis is performed by increasing PV penetration, gradually, to monitor the voltage rise scenarios at the STC. Generally, $25^{\circ} \mathrm{C}$ temperature and $1000 \mathrm{~Wb} / \mathrm{m}^{2}$ is considered as the STC condition for PV units. Till $20 \%$ PV penetration, i.e. 4 customers each having $5 \mathrm{kVA}$ units in individual test points, the LV network supports the reverse power from the PV units without causing voltage constraints and the STATCOM/BES unit can easily be applied to regulate the voltage (p.u) close to unity, if desired. When the PV penetration is increased to $50 \%$, i.e. 9 customers each having $5 \mathrm{kVA}$ units in all the 8 points, the terminal voltages at the farthest points start increasing, but do not exceed the $+6 \%$ limit. Finally, the PV penetration is increased to $70 \%$, i.e. 15 customers each having $5 \mathrm{kVA}$ units in all the 8 points, which results in the terminal voltages to exceed the limit in all the farthest points; however, the point (P3) close to the distribution transformer remains within the standard limit. The results are shown in Fig. 11 and from the figure, it is evident that the most critical voltage rise points are point 2 (P2), point 6 (P6), point 5 (P5) and point 1 (P1). As the P2 $(420 \mathrm{~m})$ and P6 (360 m) are the farthest points from the distribution transformer, it is expected that increasing PV penetration will have a higher impact on these two points. The remaining testing points, namely, point 4 (P4), point 8 (P8), and point 9 (P9) are not shown in Fig. 11, as shown in Fig. 16 (b) those points are not critically sensitive with increasing PV penetration cases.

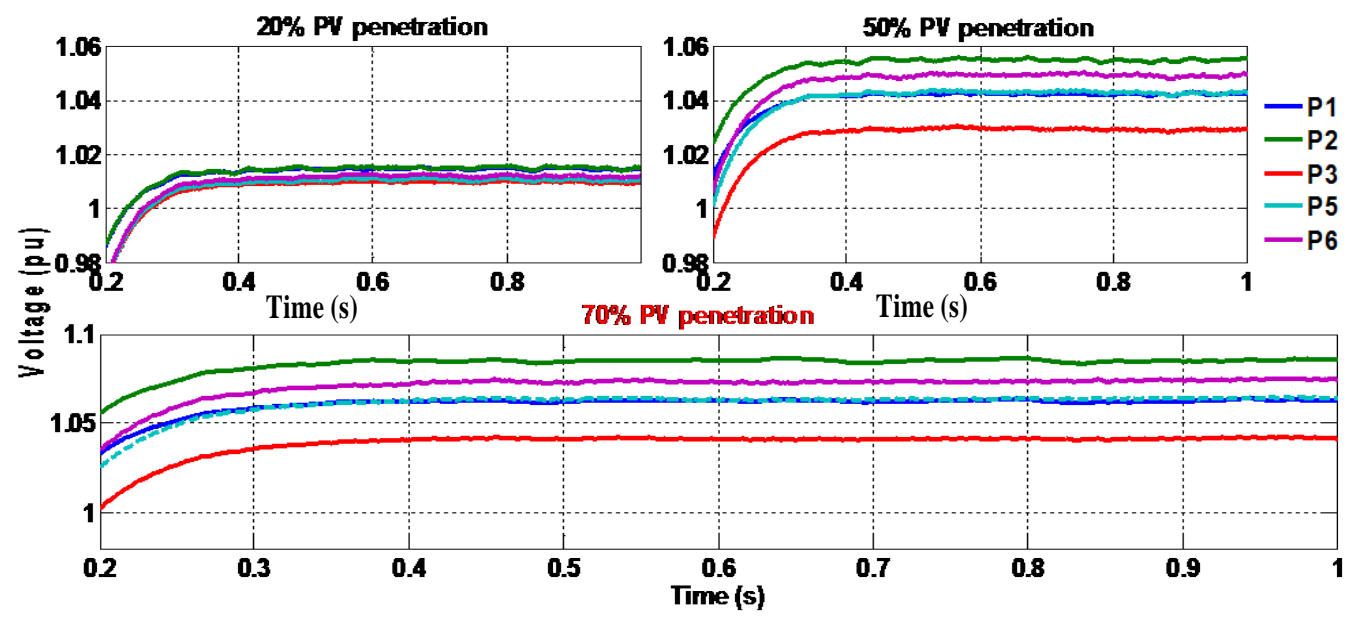

Fig. 11. Initial analysis varying PV penetration at STC. 
The distribution transformer in the LV network is an off load tap changing type. Initially, a traditional solution is applied with a highly PV penetrated network (> 85\%, 17 customers each with $5 \mathrm{kVA}$ PV units in all the 8 points) to verify the voltage regulation effects. The tap of the distribution transformer is increased from 1 to 1.025 (2.5\%) at $0.50 \mathrm{~s}$ and then to 1.05 (5\%) at $1.0 \mathrm{~s}$ as shown in Fig. 12.

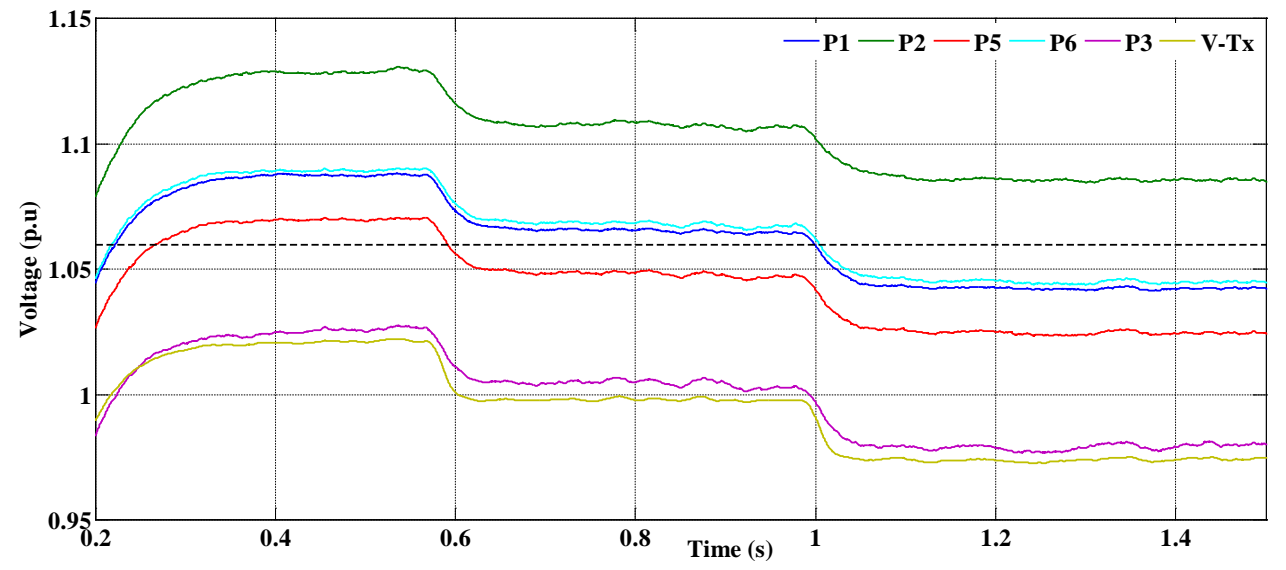

Fig. 12. OLT operation for voltage rise mitigation.

Similar to the operation of the practical LV networks, the tap changing improves the voltage profile significantly, even for the farthest corner points like P2, P6, P5, and P1. However, the P2 point still remains higher than the allowable limit, and the testing point near to the transformer, P3, faces voltage reduction less than unity. Further tap changing may improve the P2 voltage within the $+6 \%$ limit; however, it will cause the P3 voltage to go below the $-6 \%$ limit. Therefore, alternative solutions are required to improve the $\mathrm{P} 2$ area voltage prolife, while keeping other testing points within the $\pm 6 \%$ limit.

Other traditionally implemented solutions, such as capacitor banks, can be installed at the farthest points to improve the voltage profile. However, due to the slow response time from capacitor banks, sometimes it may cause unnecessary tripping; therefore it is avoided in this paper. Increasing the conductor size by replacing the existing ones can certainly increase the network capacity for more PV penetrations, but this would not be an economic solution. Moreover, centralized regulation control has less impact on highly DG penetrated networks. Therefore, different decentralized controllers are applied at the STC conditions with PV penetrations higher than 65\%, and the results are shown in Figs. 13 and 14. From the initial results, it is evident that at a PV penetration higher than 65\%, P2 voltage can only be controlled using the controller mode D and E; whereas, other testing points P1, P5 and P6 voltage can easily be controlled using any controller modes from B. Among the available controls, the optimum regulation performance is achieved using the control mode E, i.e. power sharing among neighbor DG units. From the results, it can be inferred that the testing point P2 is a most critically sensitive area with increasing PV penetrations. Therefore, the main consideration is given to P2 voltage regulations with PV penetrations higher than $50 \%$ cases. Instead of installing compensation devices throughout the LV networks, the proposed control selection methodology recommends installation of compensation devices only at the critical voltage sensitive points and improvises most economical solution for voltage regulation purposes.
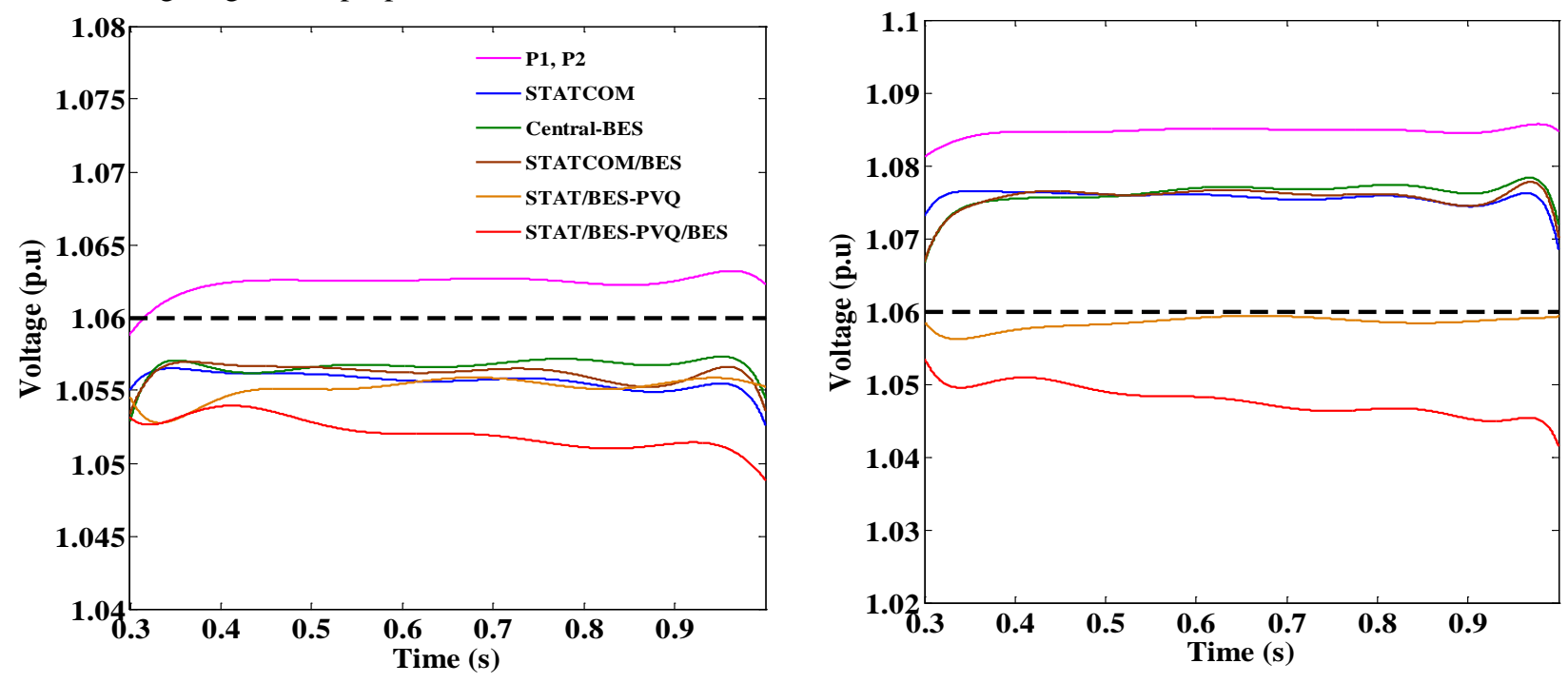

Fig. 13. Testing points P1 (left) and P2 (right) at PV penetration $>65 \%$. 

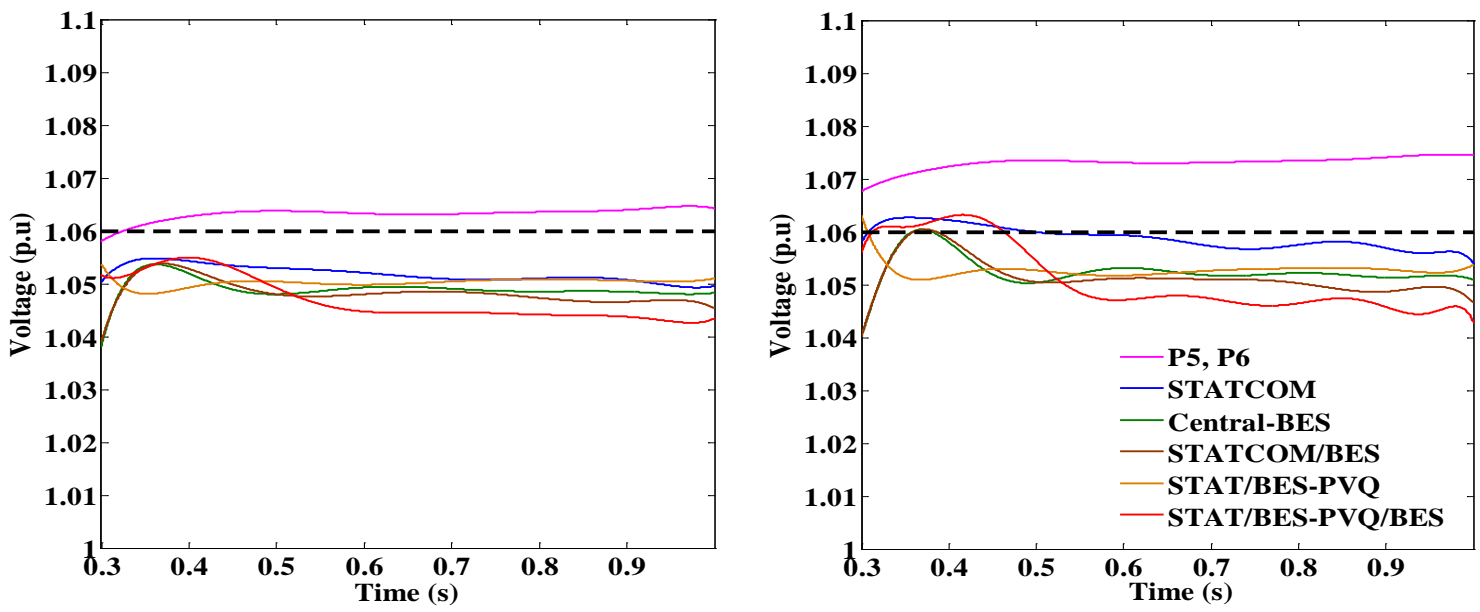

Fig. 14. Testing points P5 (left) and P6 (right) at PV penetration $>65 \%$.

\section{Initial test results with actual data for summer and winter:}

In actual DG units, environmental parameters play a significant role in producing output powers. For a PV system, stochastic irradiance, temperature variation, and cloud passing are the main parameters. The variations in irradiance in different seasons are shown in Fig. 15. The solar irradiance data is collected from the installed microgrid at Griffith University, Australia. This irradiance data is utilized for all PV units. The irradiance data is collected for three days from 6 am to 5 pm at 5 minutes' intervals in 2015. Simulation time step is considered as $50 \mu$ s, and a $1.8 \mathrm{~s}$ simulation time is represented for one day performance evaluation periods. The temperature is considered as an average of $30-35^{\circ} \mathrm{C}$ during summer and average $15-20^{\circ} \mathrm{C}$ during winter.

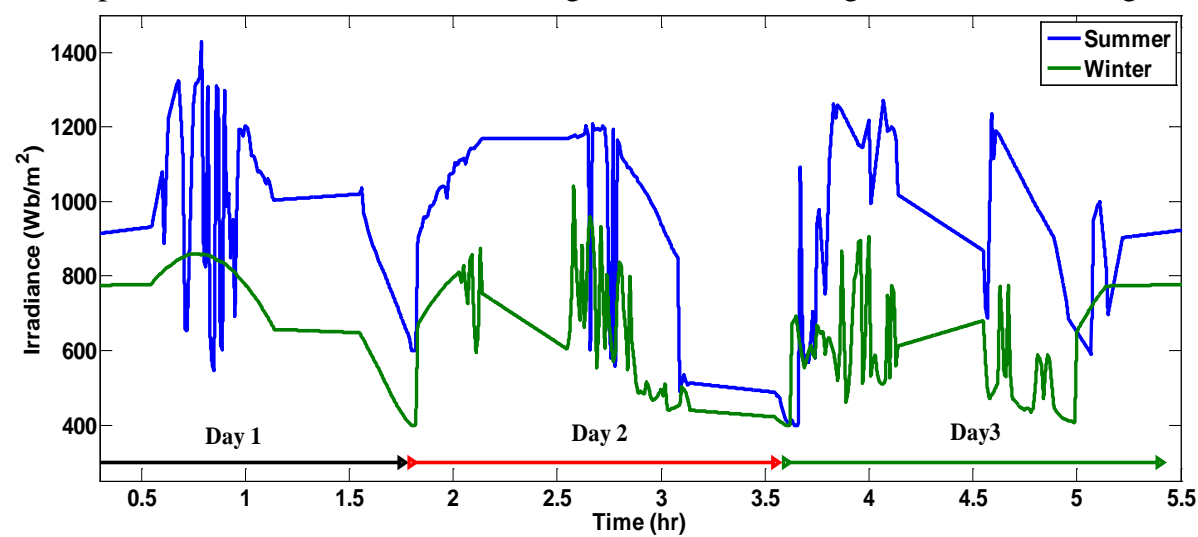

Fig. 15. Summer (29th $-31^{\text {st }}$ Jan, 2015) and winter $\left(7^{\text {th }}-9^{\text {th }}\right.$ June, 2015) irradiance.

At the PV penetration level higher than $60 \%$, the PV output powers and terminal voltages are shown in Fig. 16. The PV power output is higher during summer than winter. In both seasons, the most critical point remains P2, whereas, during summer P1, P5, and P6 exhibit voltage limit constraints. From an initial case analysis, the primary focus on controller operating mode selection is given on the farthest test points and, depending on the voltage profile improvement requirement, an additional control operation is included in the following case studies.
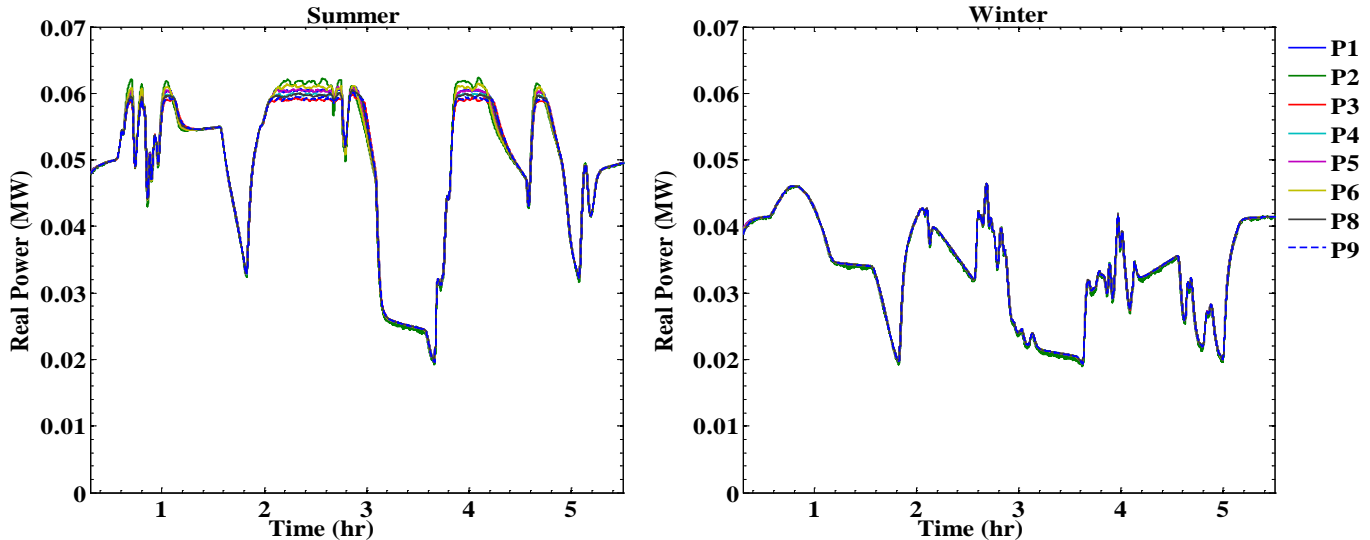

(a) 

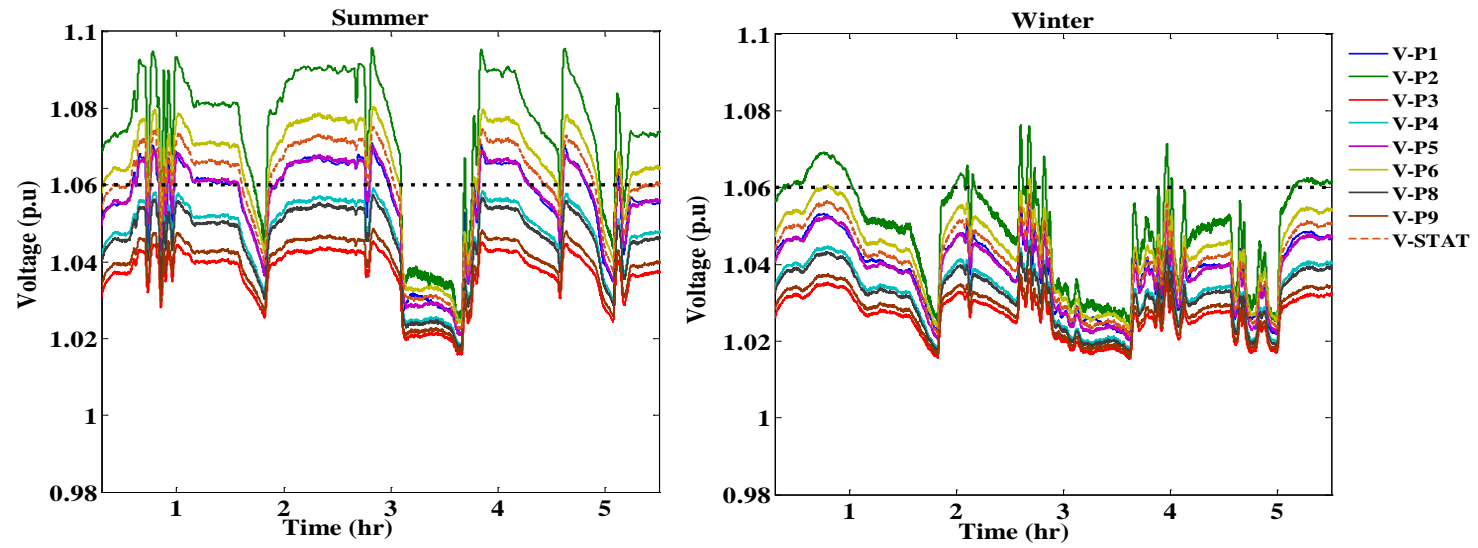

(b)

Fig. 16. (a) Active power outputs and (b) corresponding terminal voltage profiles for different seasons.

\section{D. $P V$ penetration $>50 \%$ during summer (Mode $C$ ):}

This case study shows the voltage profile improvement with PV penetrations is higher than $50 \%$ using the control mode $\mathrm{C}$ and D. Initially, the controller selects operating mode B with the STATCOM regulation and BES charging operation. The controller regulates the terminal voltages of P1, P5 and P6 as shown in Fig. 17; however, the critical point P2 remains higher than 1.06 p.u; later, control mode $\mathrm{C}$ and $\mathrm{D}$ is applied sequentially to improve the voltage at the $\mathrm{P} 2$ testing point. Each test points are considered of having 11 customers with 5 kVA PV unit installations. During peak time, one cluster PV unit delivers around $50 \mathrm{~kW}$ active power to the PCC. Following the control selection modes, installations of the smart VSI and BES in all the test points are avoided, thus, providing the best economical solution with a current PV penetration scenario. Despite the marginal voltage profile improvement using the control mode $\mathrm{C}$, at some points, it exceeds the $+6 \%$ limit. This is due to the lack of variable reactive power operations from the connecting units. Increasing the reactive power capability, the voltage can be further improved; however, it is avoided so as not to make any contradiction with the Australian connecting standards. Therefore, the control mode D, i.e. the PV smart VSI with residential BES charging operation, is applied. The result is that the voltage profile improves and becomes lower than 1.06 p.u as shown in Fig. 18. The operating mode D is only applied at P2 with less than a 6 $\mathrm{kWh}$ charging requirement and, at the same time, the remaining network is compensated by the STATCOM/BES operation.
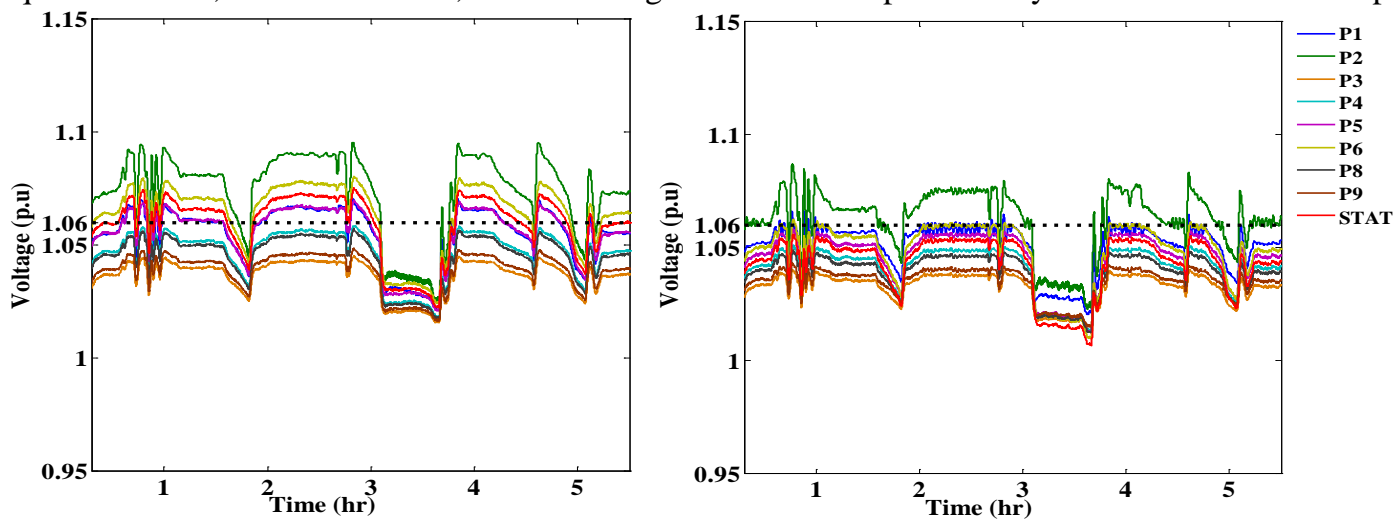

Fig. 17. Terminal voltage with no compensation (left), and STATCOM/BES (right).

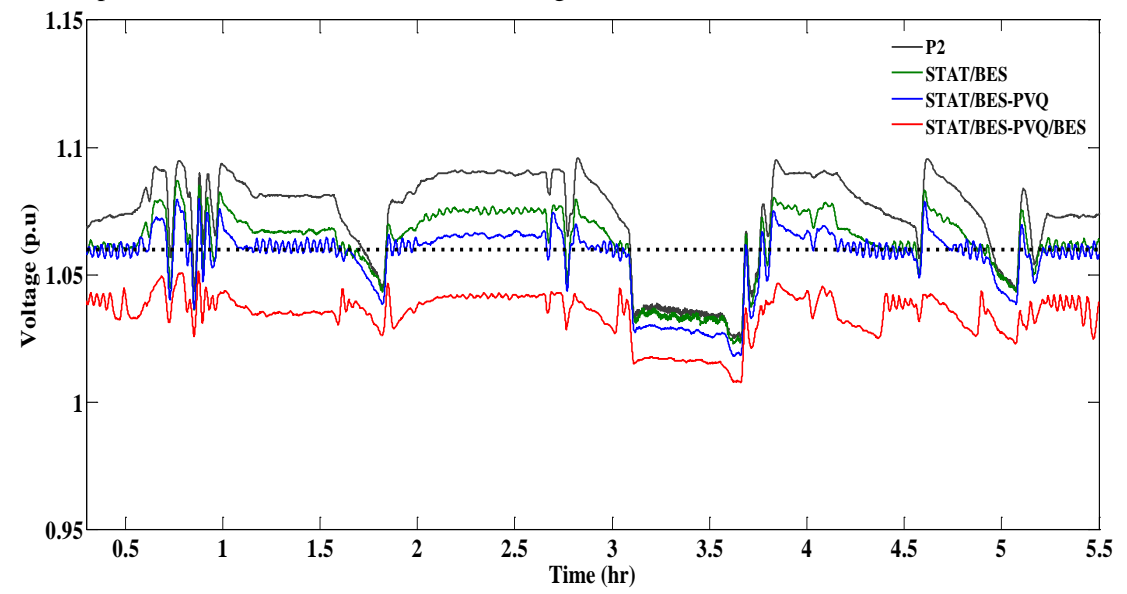

Fig. 18. Operating modes performance comparison at critical test point (P2). 
Three observation points (OP) are shown in Fig. 19 to explain the control operations at different operating modes. For this analysis, $10 \mathrm{kVAR}$ local voltage regulation from a smart PV VSI and around $6 \mathrm{kWh}$ charging supports from residential BES are considered for the P2 area. Among 11 customers at each testing points, half of the customers are considered as having unity pf VSI and half smart VSI. Therefore, a total of $10 \mathrm{kVAR}$ is available from 11 customers. With the local reactive power maximum support, operating mode $\mathrm{C}$ results in active power with a lower than rated generation, as shown in OP1.This is due to the derating operation with fixed VAR support from the VSI. However, with the operating mode D, the voltage profile shows improvement, with better power quality at the same OP1. Similar characteristics for two controllers can be observed in OP2 but in different time frames $(3.80-4.30 \mathrm{~s})$. When the terminal voltage becomes lower than 1.03 p.u, the local smart VSI VAR support is shifted to the unity pf operation mode to avoid overloading the PV VSI, as shown in OP3 in Fig. 19. At the same time, with the controller mode D, the smart VSI continues to operate at a maximum of kVA despite a lower voltage profile. This is to compensate the oscillation in power resulting from the stochastic irradiance.
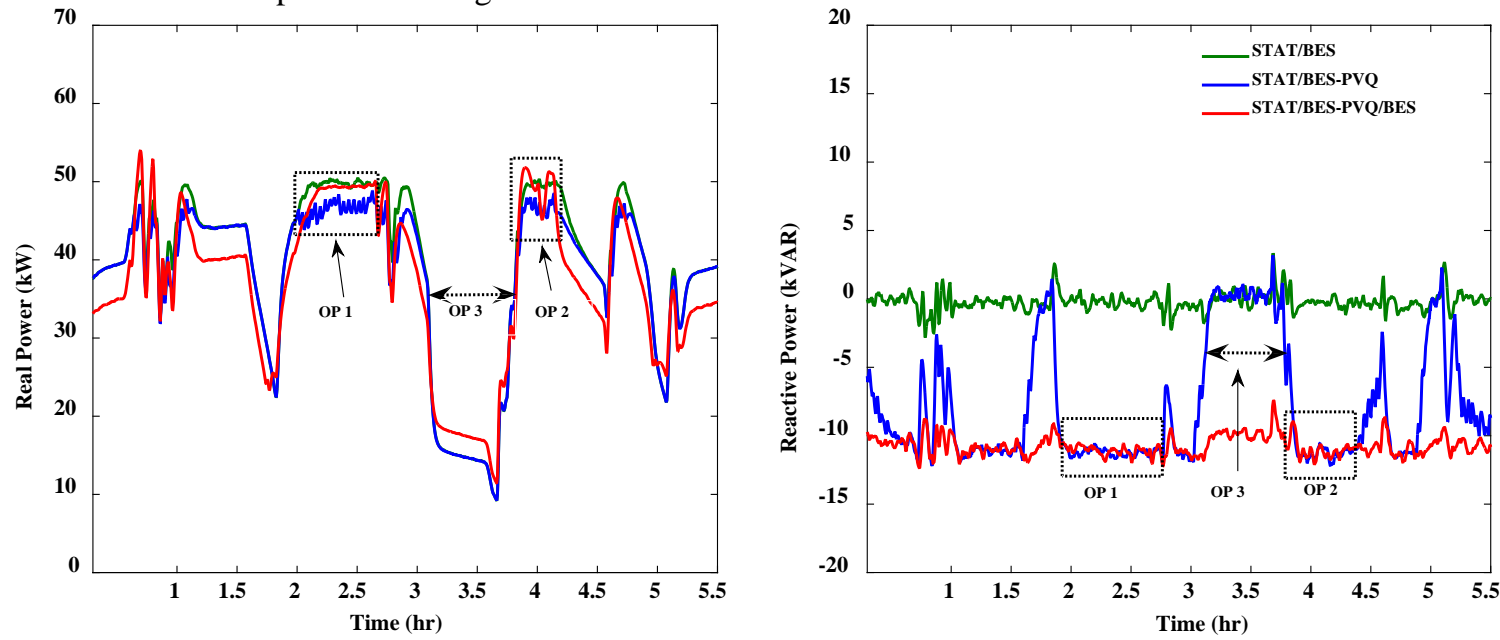

Fig. 19. Active power (left), and reactive power (right) with different modes at P2.

From this case analysis, it can be inferred that at a PV penetration higher than $50 \%$, the network requires additional compensating devices, while the combined local active and reactive power operation shows better performance than the VAR support alone. The hierarchical controls selection method reduces the capacity requirement from the BES installation when compared to BES operation alone. It is estimated that the individual BES regulation will require at least $15 \mathrm{kWh}$ charging from the P2 area to regulate the PCC voltage within limit.

\section{E. $P V$ penetration $>65 \%$ with faults (Mode $D)$ :}

This case study evaluates the overall performance improvement with the existence of STATCOM/BES for the control mode D. Different faults, like three phase to ground (3P-G) from 1.30-1.50 s, double lines ground (L-L-G) from 2.30-2.50 s, and single line to ground (L-G) faults from 4.00-4.20 s are applied at different network locations. The results for the test points P1 and P5 are shown in Figs. 20 and 21. The individual hour data (labelled at $\mathrm{x}$ axis) is modified for the simulation plot in seconds. The operating mode D is applied with the PV penetration higher than 65\% in test points P1 and P5, considering the farthest and closes locations from the faults points.
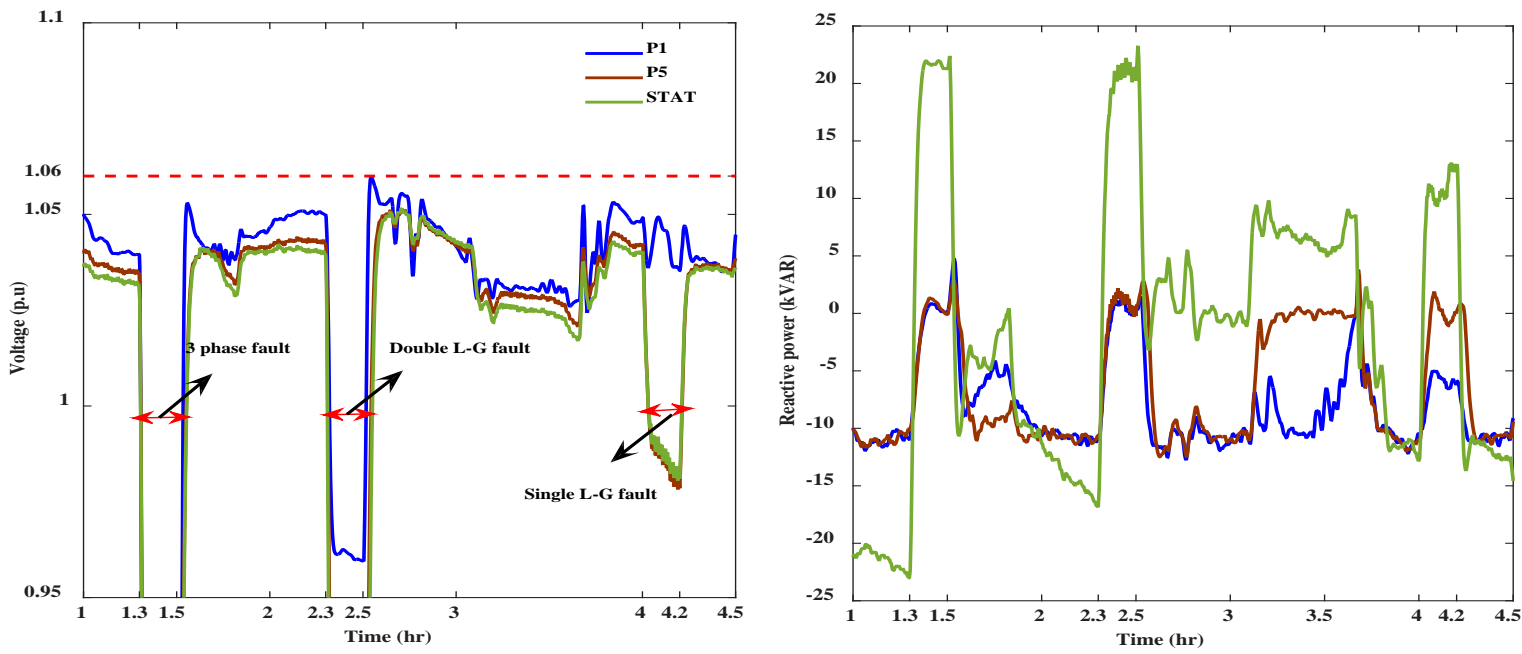

Fig. 20. Faults effect on voltages (left) and reactive power (right). 

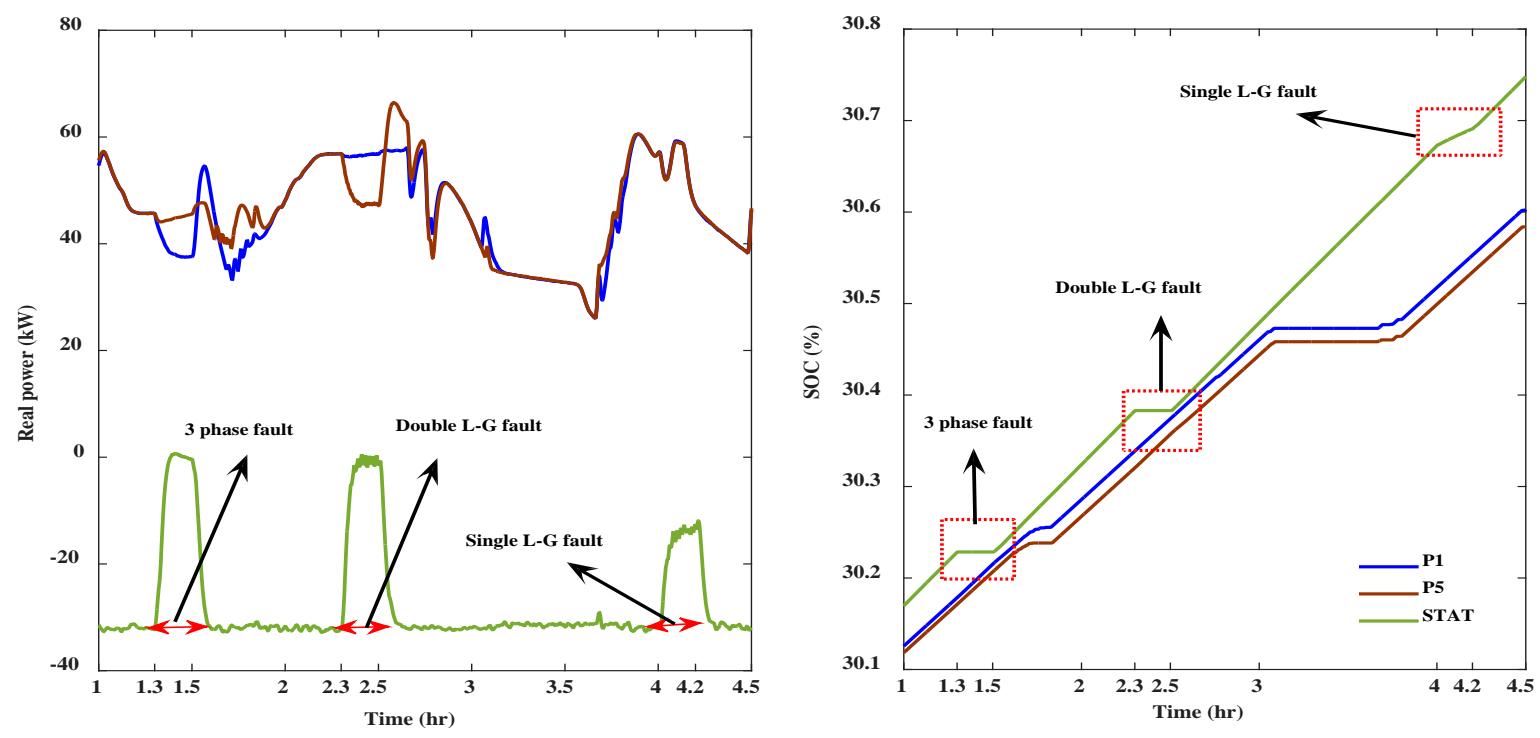

Fig. 21. Faults effects on active power (left) and battery SOC (right).

From these results, it can be seen that the STATCOM is solely supplying the required reactive power whereas the points P1 and P5 remain operating either at unity pf or at lagging pf. Also during a fault, the STATCOM/BES regulates the active power for the overall network stability improvement while keeping other PV area operations unaffected, as can be seen from the PV output powers and BES SOCs. This explains that even though the STATCOM/BES requires additional local support for critical voltage regulations in specific areas, STATCOM/BES installation in the LV network improves overall performance of the highly PV penetrated network, even in extreme disturbance scenarios.

\section{F. PV penetration $>85 \%$ during summer (Mode E):}

Despite the highest capacity regulation operation from the control mode D resources, if the voltage still violates the $+6 \%$ limit, due to higher PV penetrations, power sharing among DG units become the most optimum solution. The controller mode E is considered only for the critical test point P2 area, and the controller performance is compared without power sharing in Figs. 22 and 23. The solid lines in Figs. 22 and 23 represent the operating mode D results, while the dotted lines (P2*) represent the results after the application of operating mode $\mathrm{E}$. The controller is designed to compensate PCC voltage only after $\Delta \mathrm{V}$ exceeds 1.03 p.u. Therefore, the point 9 (P9) area remains operating in the normal control mode, despite the neighbor P2 area experiencing voltage constraints. Under the effect of controller mode E, the local controller experiencing higher voltage initiates power sharing signals for the neighbor DG units. Upon receiving the signal, the P9 area starts sharing its power to help regulate the P2 terminal voltage as shown in Figs. 22 and 23. In this case active power sharing is given priority over the reactive power sharing operations. From $1.80-2.80 \mathrm{~s}$, even with the BES charging operation, i.e. the active power sharing operation from the P9 area, the P2 requires additional support. Only then does the P9 area start sharing reactive power. Instead of increasing the capacity of local support, power sharing provides better regulation performance with existing resources.
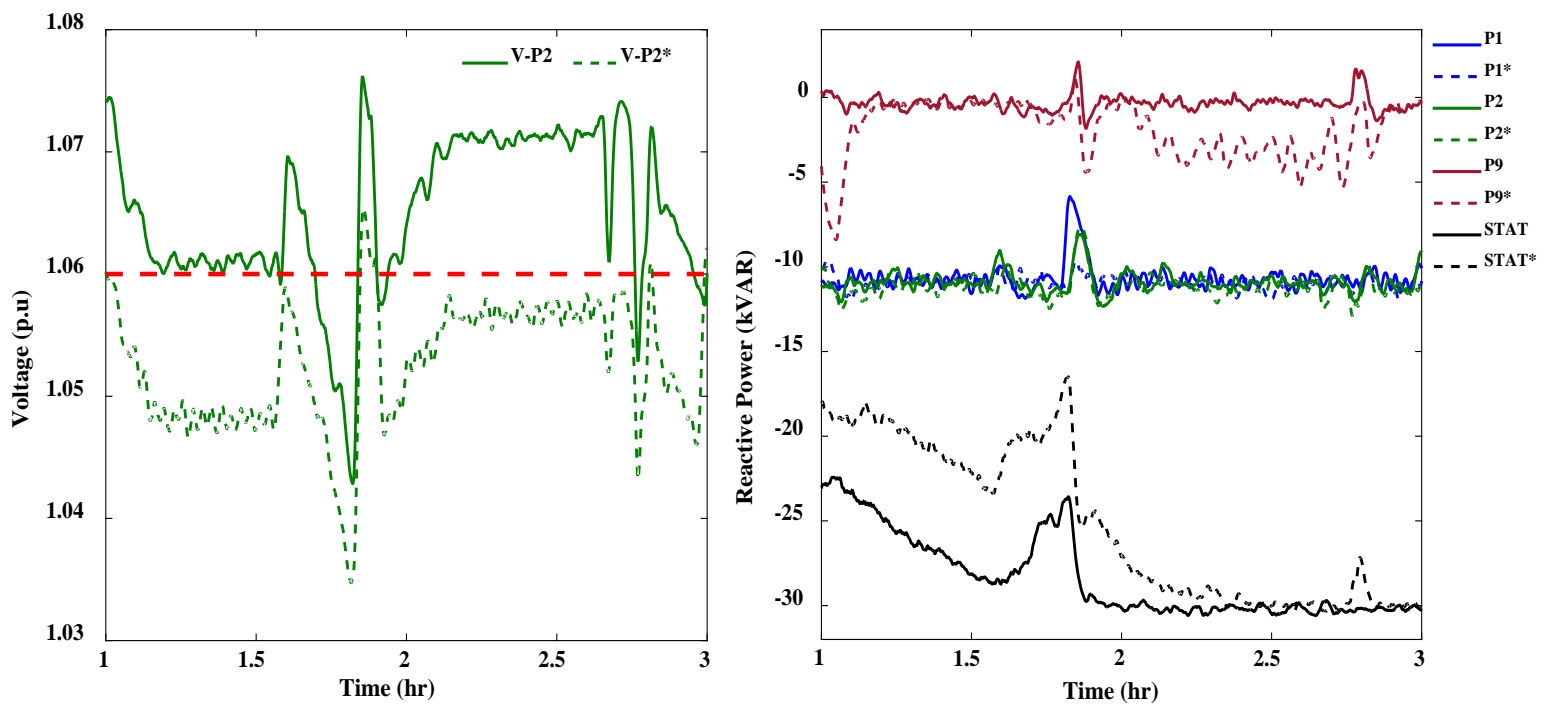

Fig. 22. Power sharing at P2 voltage (left) and reactive power (right). 

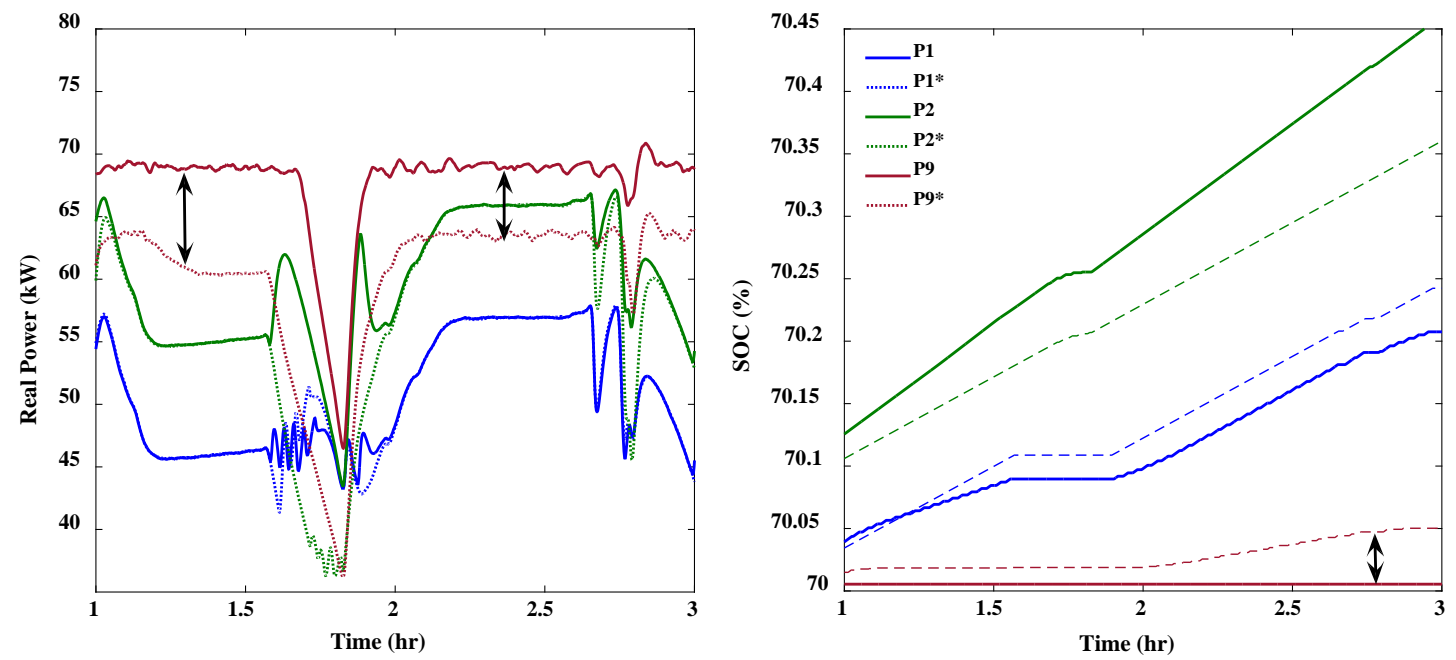

Fig. 23. Power sharing at P2, active power (left) and battery SOC (right).

A significant point of the proposed power sharing is the reduction in the decentralized support requirement from STATCOM as can be seen from the reduced VAR consumption in Fig. 23. To achieve $100 \%$ renewable energy integration, power sharing is the most economical solution for future grid networks. The applied control selection methodology helps in making proper investment decisions including from the economic perspective, as well as from the robust dynamic performance in highly DG penetrated LV networks.

\section{G. $P$ V penetration $>75 \%$ during winter:}

From the case study D, it can be seen that only the P2 area exhibits voltage constraints during winter with PV penetration higher than $60 \%$. In such a situation, according to the proposed method, control modes $\mathrm{C}$ and $\mathrm{D}$ would be sufficient to stabilize the voltage issues. With the operating mode E enabled during winter, the network is capable of providing support for both the voltage regulations and the power quality improvement. From $0.60-1.00 \mathrm{~s}$, the system operates initially at mode D as the voltage remains below 1.06 p.u. However, as highlighted in the Fig. 24, the power sharing is enabled for the OP2 and OP3 sections to help reduce the oscillations which resulted from the stochastic irradiance from the PV units. The proposed methodology minimizes the power sharing complexity of the multiple loops networks and shows a better regulation performance with minimum device requirements for a highly PV penetrated LV network.

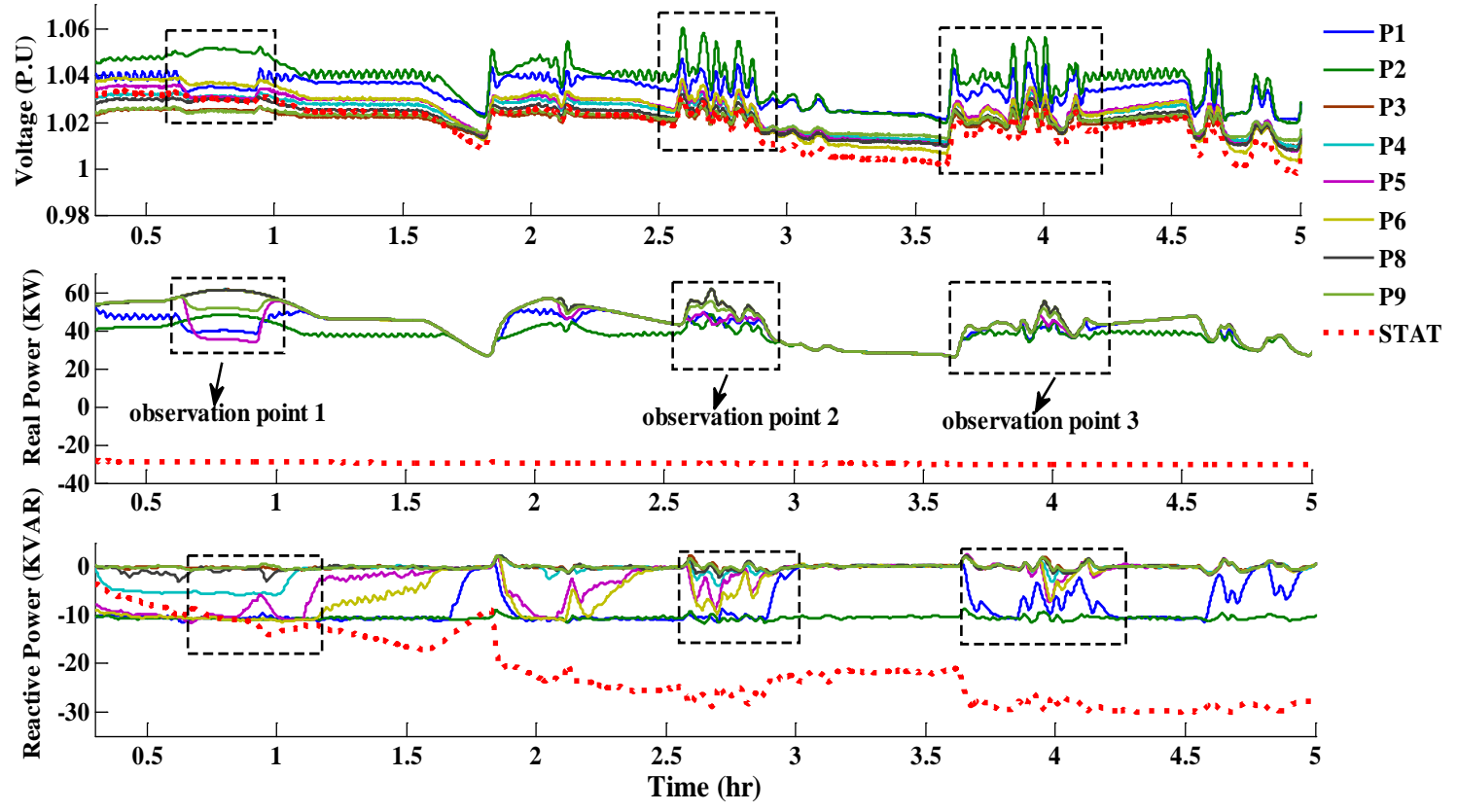

Fig. 24. LV network with PV penetration $>75 \%$ during winter.

\section{COST COMPARISON}

In conjunction with the policies enacted by governments in Australia, the solar PV cost reduction from AU\$12 to AU\$2 per 
watt contributed significantly to the number of PV installations [45]. Following this scenario, the installation numbers can be anticipated to increase more significantly in the upcoming years. For a control methodology to be effective in real life applications, it needs to be robust in performance, as well as cost effective when compared with existing methodologies.

A simplistic comparative cost analysis has been conducted for the proposed hierarchical controls selection method. The standard pricing for the VAR requirement is considered as US\$ 50-55/kVAR, with the BES units being 400 US \$/KWh for a zinc-bromide ( $\mathrm{ZnBr}$ ) flow battery [41] [46]. For the control mode A and B, the STATCOM (30 kVA) and BES (30 kWh) price would be around 13,500 US\$. If decentralized controls were applied from the PV penetrations condition higher than $30 \%$, it would require the smart VSI and BES to be installed in the 6 testing points, except for P3 and P4, as those are close to the distribution transformer. At a PV penetration higher than 50\%, each cluster point would require at least $20 \mathrm{kVAR}$ or $15 \mathrm{kWh}$ BES charging operation support operation to regulate the terminal voltage at each test point. For one cluster point, smart VSI total cost would be around 1000 US\$ and for BES installation 6000 US\$. Considering 6 testing points, the total installation cost would be 6000 US\$ for smart VSI and 36,000 US\$ for BES operation alone. With the proposed methodology, the operating mode C (PV penetration $>50 \%$ ) requires local regulation at critical points only after the STATCOM/BES compensation operation resulting in less device installation requirements than the decentralized operation alone. Moreover, as the proposed method considers both DNO's (STATCOM/BES) and customers' interactive support operation, the overall cost is expected to be much less than the individual regulation operations. From the test results and cost analysis, it can be concluded that the proposed methodology presents a robust dynamic voltage improvement, as well as a cost effective solution, in comparison with the individual operation from centralized or other decentralized methods.

\section{CONCLUSION}

A hierarchical control selection method is presented in this paper for mitigating voltage rise problems associated with incremental PV penetrations into the LV networks. From the initial investigation, it has been found that, when the PV penetration levels exceed a certain level, for example in this paper more than 30\%, the considered LV network exhibits voltage constraints, especially at the farthest customer points from the distribution transformer. With the application of the proposed control method, the voltage constraint issues from different PV penetration levels are mitigated accordingly using the coordinated operation of the DER units. The economic and technical justification of the proposed control method has also been presented in this paper. It is found that, rather than installing dynamic compensations at all the testing points, the proposed compensation techniques, only at critical points, can provide stable and economic operations of the considered LV network. The future aim of this research is to design and apply robust unbalanced controllers for the unbalanced LV networks using the smart VSI for the secure and economic operation of LV networks.

\section{ACKNOWLEDGEMENT}

The authors of this paper forward their sincerest thanks to ENERGEX, the electric power distribution company owned by the Queensland government, Australia, for providing the distribution network model for this research study.

\section{APPENDIX}

Table 1: Distance from DT to testing points

\begin{tabular}{|l|l|}
\hline Points & Distance \\
\hline Upstream to $\mathrm{T}_{\mathrm{dx}}$ & $1.5 \mathrm{~km}$ \\
\hline $\mathrm{T}_{\mathrm{dx}}$ to P1 & $260 \mathrm{~m}$ \\
\hline P2 & $420 \mathrm{~m}$ \\
\hline P3 & $90 \mathrm{~m}$ \\
\hline P4 & $180 \mathrm{~m}$ \\
\hline P5 & $220 \mathrm{~m}$ \\
\hline P6 & $360 \mathrm{~m}$ \\
\hline STATCOM/BES & $355 \mathrm{~m}$ \\
\hline P8 & $160 \mathrm{~m}$ \\
\hline P9 & $100 \mathrm{~m}$ \\
\hline
\end{tabular}

Table 2: Overhead cable specification

\begin{tabular}{|c|c|c|c|}
\hline Cable no. & $\begin{array}{c}\text { Cable Material/ } \\
\text { code name }\end{array}$ & Specifications & Total cable installed length \\
\hline 1 & Moon & $\begin{array}{c}\text { Overall diameter (OD) }-14.3 \\
\text { Strands No./Dia-7/4.75, } \\
\text { Line impedance } 0.232 \Omega / \mathrm{km}\end{array}$ & $\begin{array}{c}\text { Upstream network (UN)-850 m } \\
\text { LV network }-130 \mathrm{~m}\end{array}$ \\
\hline 2 & $\begin{array}{c}\text { Hard drawn bare } \\
\text { copper (HDBC) } 1\end{array}$ & $\begin{array}{c}\text { (OD)- } 6.1 \mathrm{~mm} \\
\text { Strands No./Dia-7/.080; } \\
\text { Line impedance } 0.816 \Omega / \mathrm{km}\end{array}$ & $\mathrm{UN}-620 \mathrm{~m}$ \\
\hline
\end{tabular}




\begin{tabular}{|c|c|c|c|}
\hline 3 & Wasp & $\begin{array}{c}\text { OD } 13.18 \mathrm{~mm} \\
\text { Strands No./Dia.7/0.173, } \\
\text { Line impedance } 0.27 \Omega / \mathrm{km}\end{array}$ & LV - $360 \mathrm{~m}$ \\
\hline 4 & Fly & $\begin{array}{l}\text { CSA- } 64 \mathrm{~mm}^{2} \text {, OD } 10.21 \mathrm{~mm} \text {, } \\
\text { Strands No./Dia. } 7 / .134, \\
\text { Line impedance- } 0.45 \Omega / \mathrm{km}\end{array}$ & LV -170m \\
\hline 5 & Mars & $\begin{array}{l}\text { CSA-77.31mm², OD-11.3mm, } \\
\text { Strands No./Dia-7/3.75; } \\
\text { Line impedance } 0.37 \Omega / \mathrm{km}\end{array}$ & LV - 60m \\
\hline 7 & HDBC cable 2 & $\begin{array}{l}\text { Conductor size } 7 / 0.104 \\
\text { OD- } 7.92 \mathrm{~mm}, \\
\text { Dc resistance- } 0.45 / \mathrm{km}\end{array}$ & LV $-340 \mathrm{~m}$ \\
\hline 8 & HDBC cable 3 & $\begin{array}{c}\text { OD-6.1 mm, } \\
\text { Conductor size -7/.080; } \\
\text { Line impedance } .816 \Omega / \mathrm{km}\end{array}$ & LV $-490 m$ \\
\hline 9 & HDBC cable 4 & $\begin{array}{c}\text { OD - } 10.54 \mathrm{~mm} \text {, } \\
\text { Conductor size }-19 / 0.083 \\
\text { Line impedance } 0.278 / \mathrm{km}\end{array}$ & LV -130 m \\
\hline 10 & HDBC cable 5 & $\begin{array}{c}\text { OD- } 8.2 \mathrm{~mm} \\
\text { Conductor size } 19 / 0.064 \\
\text { Line impedance } 0.466 / \mathrm{km}\end{array}$ & LV -50 m \\
\hline
\end{tabular}

Table 3: Designed components specifications

\begin{tabular}{|c|c|}
\hline Components & Specifications \\
\hline \multicolumn{2}{|l|}{ PV modules } \\
\hline $50 \%$ penetration & $\begin{array}{l}\text { No of series module }=10 \\
\text { No of parallel module }=6 \\
\text { Current limit }=+70 \mathrm{~A}\end{array}$ \\
\hline$>65 \%$ penetration & $\begin{array}{l}\text { No of series module }=10 \\
\text { No of parallel module }=8 \\
\text { Current limit }=+100 \mathrm{~A}\end{array}$ \\
\hline$>85 \%$ penetration & $\begin{array}{l}\text { No of series module }=10 \\
\text { No of parallel module }=12 \\
\text { Current limit }=+130 \mathrm{~A}\end{array}$ \\
\hline Dc voltage & $600-800 \mathrm{~V}$ \\
\hline Dc link capacitor & $2000 \mu \mathrm{F}$ \\
\hline Switching frequency and time step & $3 \mathrm{kHz}$ and $5 \mathrm{~ms}$ \\
\hline Dc voltage regulator & $\mathrm{Kp}=5, \mathrm{Ti}=0.008$ \\
\hline Internal current controller & $\mathrm{Kp}=8, \mathrm{Ti}=0.003$ \\
\hline LCL filter & $\begin{array}{l}\text { Linverter }=4 \mathrm{mH} ; \mathrm{C}_{\text {filter }}=10 \mu \mathrm{F} ; \\
\text { Lgrid }=1 \mathrm{mH} ; \mathrm{Rd}=1 \mathrm{~m} \Omega\end{array}$ \\
\hline \multicolumn{2}{|l|}{ STATCOM } \\
\hline Dc voltage regulator & Active Current limiter $\pm 60 \mathrm{~A}$ \\
\hline PI gain values & $\mathrm{Kp}=2, \mathrm{Ti}=0.8$ \\
\hline RMS voltage regulator & Reactive current limiter $= \pm 60 \mathrm{~A}$ \\
\hline PI gain values & $\mathrm{Kp}=2, \mathrm{Ti}=0.8$ \\
\hline LC filter & $\mathrm{L}=4 \mathrm{mH} ; \mathrm{C}=20 \mu \mathrm{F} ; \mathrm{Rd}=3 \mathrm{~m} \Omega$ \\
\hline Switching frequency & $3 \mathrm{kHz}$ \\
\hline \multicolumn{2}{|l|}{ BES } \\
\hline Nominal Voltage & $320 \mathrm{~V}$ \\
\hline Initial SOC & $70 \%$ \\
\hline Rated capacity & $6.5 \mathrm{Ah}$ \\
\hline Nominal discharge current & $20 \%$ \\
\hline Fully charged voltage & 1.15 p.u \\
\hline Resistive drop & 0.005 p.u \\
\hline \multicolumn{2}{|l|}{ LV Grid } \\
\hline Grid voltage & $415 \mathrm{~V} / 240 \mathrm{~V}$ \\
\hline Distribution transformer rating & $\begin{array}{l}11 \mathrm{kV} / 415 \mathrm{~V}, 750 \mathrm{KVA} \text {, } \\
\text { leakage reactance } .04 \text { p.u }\end{array}$ \\
\hline No of customers & 150 \\
\hline Total area length & Approx. 2 km \\
\hline
\end{tabular}

\section{REFERENCES}

[1] Leão RPS, Barroso GC, Sampaio RF, Almada JB, Lima CFP, Rego MCO, et al. The future of low voltage networks: Moving from passive to active. Int J Electr Power Energy Syst 2011;33:1506-12.

[2] Kundur P. Power System Stability and Control. vol. 23. 2006.

[3] REN21. Renewables 2013 Global Status Report. 2013.

[4] Australian Energy Market Operator. (2012). Rooftop PV information paper [Online].

Available:http://www.aemo.com.au/Electricity/ /media/Files/Other/forecasting/Rooftop_PV_Information_Paper.ashx.

[5] None B. PV integration on Australian distribution networks. Literature Review by The Australian PV Association, September 2013. 
[6] Ellis A, Nelson R, Von Engeln E, MacDowell J, Casey L, Seymour E, et al. Reactive power performance requirements for wind and solar plants. 2012 IEEE Power Energy Soc. Gen. Meet., 2012, p. 1-8.

[7] Shaping Australia’s Energy Future: National Cost Benefit Assessment. Smart Grid Smart City final report, AusGrid, July, 2014.

[8] IEEE P1547.8 Recommended Practice for Establishing Methods and Procedures that Provide Supplemental Support for Implementation Strategies for Expanded Use of IEEE Standard 1547. Available: http:/grouper.ieee.org/groups/scc21/1547.8/1547.8_index.html.

[9] Yang Z, Shen C, Zhang L, Crow ML, Atcitty S. Integration of a StatCom and battery energy storage. IEEE Trans Power Syst 2001;16:254-60.

[10] Chen CS, Lin CH, Hsieh WL, Hsu CT, Ku TT. Enhancement of PV penetration with DSTATCOM in taipower distribution system. IEEE Trans Power Syst 2013;28:1560-7.

[11] Jashfar S, Esmaeili S. Volt/var/THD control in distribution networks considering reactive power capability of solar energy conversion. Int J Electr Power Energy Syst 2014;60:221-33.

[12] Masters CL. Voltage rise: the big issue when connecting embedded generation to long $11 \mathrm{kV}$ overhead lines. Power Eng J $2002 ; 16: 5$.

[13] Ratnam EL, Weller SR, Kellett CM. Scheduling residential battery storage with solar PV: Assessing the benefits of net metering. Appl Energy 2015;155:881-91.

[14] Moshövel J, Kairies K-P, Magnor D, Leuthold M, Bost M, Gährs S, et al. Analysis of the maximal possible grid relief from PV-peak-power impacts by using storage systems for increased self-consumption. Appl Energy 2015;137:567-75.

[15] Alam MJE, Muttaqi KM, Sutanto D. Mitigation of rooftop solar PV impacts and evening peak support by managing available capacity of distributed energy storage systems. IEEE Trans Power Syst 2013;28:3874-84.

[16] Zhao J, Kucuksari S, Mazhari E, Son YJ. Integrated analysis of high-penetration PV and PHEV with energy storage and demand response. Appl Energy 2013;112:35-51.

[17] Tonkoski R, Lopes L a C, El-Fouly THM. Coordinated active power curtailment of grid connected PV inverters for overvoltage prevention. IEEE Trans Sustain Energy 2011;2:139-47.

[18] Tonkoski R, Lopes LAC. Impact of active power curtailment on overvoltage prevention and energy production of PV inverters connected to low voltage residential feeders. Renew Energy 2011;36:3566-74.

[19] Kolenc M, Papič I, Blažič B. Coordinated reactive power control to achieve minimal operating costs. Int J Electr Power Energy Syst 2014;63:1000-7.

[20] Scott NC, Atkinson DJ, Morrell JE. Use of load control to regulate voltage on distribution networks with embedded generation. IEEE Trans Power Syst 2002;17:510-5.

[21] Ji J, Wang Y, Yuan W, Sun W, He W, Guo C. Experimental comparison of two PV direct-coupled solar water heating systems with the traditional system. Appl Energy 2014;136:110-8.

[22] Cagnano a., De Tuglie E. Centralized voltage control for distribution networks with embedded PV systems. Renew Energy 2015;76:173-85.

[23] Turitsyn K, Šulc P, Backhaus S, Chertkov M. Options for control of reactive power by distributed photovoltaic generators. Proc IEEE 2011;99:106373.

[24] Yazdani A, Di Fazio AR, Ghoddami H, Russo M, Kazerani M, Jatskevich J, et al. Modeling guidelines and a benchmark for power system simulation studies of three-phase single-stage photovoltaic systems. IEEE Trans Power Deliv 2011;26:1247-64.

[25] Aly MM, Abdel-Akher M, Ziadi Z, Senjyu T. Assessment of reactive power contribution of photovoltaic energy systems on voltage profile and stability of distribution systems. Int J Electr Power Energy Syst 2014;61:665-72.

[26] Yan R, Saha TK. Investigation of voltage stability for residential customers due to high photovoltaic penetrations. IEEE Trans Power Syst 2012;27:651-62.

[27] Vovos PNP, Kiprakis AE a. EA, Wallace a. RR, Harrison GPGP. Centralized and Distributed Voltage Control: Impact on Distributed Generation Penetration. IEEE Trans Power Syst 2007;22:476-83.

[28] Ahn C, Peng H. Decentralized voltage control to minimize distribution power loss of microgrids. IEEE Trans Smart Grid 2013;4:1297-304.

[29] Papaioannou IT, Purvins A, Tzimas E. Demand shifting analysis at high penetration of distributed generation in low voltage grids. Int J Electr Power \{\&\} Energy Syst 2013;44:540-6.

[30] Olivier F, Aristidou P, Ernst D, Van Cutsem T. Active Management of Low-Voltage Networks for Mitigating Overvoltages Due to Photovoltaic Units. IEEE Trans Smart Grid 2015;PP:1.

[31] Kabir MN, Mishra Y, Ledwich G, Xu Z, Bansal RC. Improving voltage profile of residential distribution systems using rooftop PVs and Battery Energy Storage systems. Appl Energy 2014;134:290-300.

[32] Collins L, Ward JK. Real and reactive power control of distributed PV inverters for overvoltage prevention and increased renewable generation hosting capacity. Renew Energy 2015;81:464-71.

[33] Connection Guideline Small Scale Parallel Inverter Energy Systems up to 30 kVA in Ergon Energy and Energex network. https://www.energex.com.au/_data/assets/pdf_file/0007/199951/Draft Connection-Standard-Small-Scale-Invertor-Energy-Systems-v1.pdf)

[34] Galli S, Scaglione A, Wang Z. Power Line Communications and the Smart Grid. First IEEE Int Conf Smart Grid Commun 2010:303-8.

[35] Schauder C, Mehta H. Vector analysis and control of advanced static VAR compensators. IEE Proc C Gener Transm Distrib 1993;140:299.

[36] Hossain MJ, Saha TK, Mithulananthan N, Pota HR. Robust control strategy for PV system integration in distribution systems. Appl Energy 2012;99:355-62.

[37] Aziz T, Hossain MJ, Saha TK, Mithulananthan N. VAR planning with tuning of STATCOM in a DG integrated industrial system. IEEE Trans Power Deliv 2013;28:875-85.

[38] Pogaku N, Prodanović M, Green TC. Modeling, analysis and testing of autonomous operation of an inverter-based microgrid. IEEE Trans Power Electron 2007;22:613-25.

[39] Reznik A, Simoes MG, Al-Durra A, Muyeen SM. LCL Filter design and performance analysis for grid-interconnected systems. IEEE Trans Ind Appl 2014;50:1225-32.

[40] Tremblay O, Dessaint L a. Experimental validation of a battery dynamic model for EV applications. World Electr Veh J 2009;3:1-10.

[41] Huff G, Currier AB, Kaun BC, Rastler DM, Chen SB, Bradshaw DT, et al. DOE/EPRI 2013 electricity storage handbook in collaboration with NRECA. Rep SAND2013- \{...\} 2013:340.

[42] Thomas PR. American Electric Power Community Energy Storage. IEEE Power Engineering Society Energy Storage (Super Session), 2011.

[43] Grid connection of energy system via inverter (draft). Clean Energy council, Australia, 2013.

[44] Rafi FHM, Hossain MJ, Leskarac D, Lu J. Reactive power management of a AC/DC microgrid system using a smart PV inverter. Power Energy Soc Gen Meet 2015 IEEE 2015:1-5.

[45] Mountain B, Szuster P. Solar, Solar Everywhere: Opportunities and Challenges for Australia’s Rooftop PV Systems. Power Energy Mag IEEE 2015;13:53-60.

[46] Molinas M, Suul JA, Undeland T. Low voltage ride through of wind farms with cage generators: STATCOM versus SVC. IEEE Trans Power Electron 2008;23:1104-17. 